\title{
Distribution of lead in single atmospheric particles
}

\author{
D. M. Murphy ${ }^{1}$, P. K. Hudson ${ }^{1,2, *}$, D. J. Cziczo ${ }^{4}$, S. Gallavardin ${ }^{4}$, K. D. Froyd ${ }^{1,2}$, M. V. Johnston ${ }^{5}$, \\ A. M. Middlebrook ${ }^{1}$, M. S. Reinard ${ }^{5}$, D. S. Thomson ${ }^{1,2}$, T. Thornberry ${ }^{1,2}$, and A. S. Wexler ${ }^{6}$ \\ ${ }^{1}$ Earth System Research Laboratory, NOAA, Boulder, CO 80305, USA \\ ${ }^{2}$ Cooperative Institute for Research in the Environmental Sciences, Boulder, CO 80309, USA \\ * now at Department of Chemistry, University of Iowa, Iowa City, IA 52242, USA \\ ${ }^{4}$ Institute for Atmosphere and Climate Science, ETH, Zurich 8092, Switzerland \\ ${ }^{5}$ Department of Chemistry, University of Delaware, Newark, DE 19716, USA \\ ${ }^{6}$ Departments of Mechanical and Aeronautical Engineering, Civil and Environmental Engineering, and Land, Air and Water \\ Resources, University of California, Davis, CA 95616, USA
}

Received: 14 February 2007 - Published in Atmos. Chem. Phys. Discuss.: 13 March 2007

Revised: 23 May 2007 - Accepted: 23 May 2007 - Published: 21 June 2007

\begin{abstract}
Three independent single particle mass spectrometers measured $\mathrm{Pb}$ in individual aerosol particles. These data provide unprecedented sensitivity and statistical significance for the measurement of $\mathrm{Pb}$ in single particles. This paper explores the reasons for the frequency of $\mathrm{Pb}$ in fine particles now that most gasoline is unleaded. Trace amounts of $\mathrm{Pb}$ were found in 5 to $25 \%$ of 250 to $3000 \mathrm{~nm}$ diameter particles sampled by both aircraft and surface instruments in the eastern and western United States. Over 5\% of particles at a mountain site in Switzerland contained $\mathrm{Pb}$. Particles smaller than $100 \mathrm{~nm}$ with high $\mathrm{Pb}$ content were also observed by an instrument that was only operated in urban areas. Lead was found on all types of particles, including $\mathrm{Pb}$ present on biomass burning particles from remote fires. Less common particles with high $\mathrm{Pb}$ contents contributed a majority of the total amount of $\mathrm{Pb}$. Single particles with high $\mathrm{Pb}$ content often also contained alkali metals, $\mathrm{Zn}, \mathrm{Cu}, \mathrm{Sn}, \mathrm{As}$, and $\mathrm{Sb}$. The association of $\mathrm{Pb}$ with $\mathrm{Zn}$ and other metals is also found in IMPROVE network filter data from surface sites. Sources of airborne $\mathrm{Pb}$ in the United States are reviewed for consistency with these data. The frequent appearance of trace $\mathrm{Pb}$ is consistent with widespread emissions of fine $\mathrm{Pb}$ particles from combustion sources followed by coagulation with larger particles during long-range transport. Industrial sources that directly emit $\mathrm{Pb}$-rich particles also contribute to the observations. Clean regions of the western United States show some transport of $\mathrm{Pb}$ from Asia but most $\mathrm{Pb}$ over the United States comes from North American sources. Resuspension of $\mathrm{Pb}$ from soil contaminated by the years of leaded gasoline was not directly apparent.
\end{abstract}

Correspondence to: D. M. Murphy

(daniel.m.murphy@noaa.gov)

\section{Introduction}

Lead $(\mathrm{Pb})$ is a highly toxic metal with wide industrial uses. There was widespread lead pollution during the last century and even extending back to ancient civilizations. Lead pollution is so widespread that there is essentially no surface soil that is uncontaminated with $\mathrm{Pb}$ (Shotyk and $\mathrm{Le}$ Roux, 2005). There is extensive literature on lead pollution and on airborne lead in particular. The nearly worldwide elimination of leaded gasoline has drastically changed the sources and fluxes of $\mathrm{Pb}$. For example, airborne lead in the United States has decreased by a factor of 20 or more since 1980 (EPA, 2003). Airborne Pb in Shanghai dropped from about 500 to $200 \mathrm{ng} \mathrm{m}^{-3}$ after the phaseout of leaded gasoline there (Tan et al., 2006). The progression from the years of leaded gasoline can also be measured using isotopic signatures (e.g. Widory et al., 2004). Therefore, much of the older literature on airborne $\mathrm{Pb}$ is (fortunately) not very relevant to today's atmosphere. Despite the large decreases in emissions, there are still substantial sources of $\mathrm{Pb}$ pollution. For example, the flux of $\mathrm{Pb}$ to the arctic is still dominated by anthropogenic inputs (Shotyk et al., 2005). Airborne $\mathrm{Pb}$ concentrations can still exceed $1 \mu \mathrm{g} \mathrm{m}^{-3}$ near point sources such as the smelter in Herculaneum, Missouri (http://www.dnr.mo.gov/env/esp/aqm/herculaneum.htm).

Lead and its common sulfur and oxygen compounds are solids at room temperature. Therefore, airborne $\mathrm{Pb}$ is predominately particulate, with at most a few percent present as gas phase alkyl compounds (Wang et al., 1997; Shotyk and Le Roux, 2005). In most places most of the $\mathrm{Pb}$ is on particles smaller than $1 \mu \mathrm{m}$ diameter. This was the case in Ghent, Belgium (Maenhaut et al., 2002), Budapest, Hungary (Salma et al., 2002), Gosan, Korea (Han et al., 2005), and Seville,

Published by Copernicus Publications on behalf of the European Geosciences Union. 


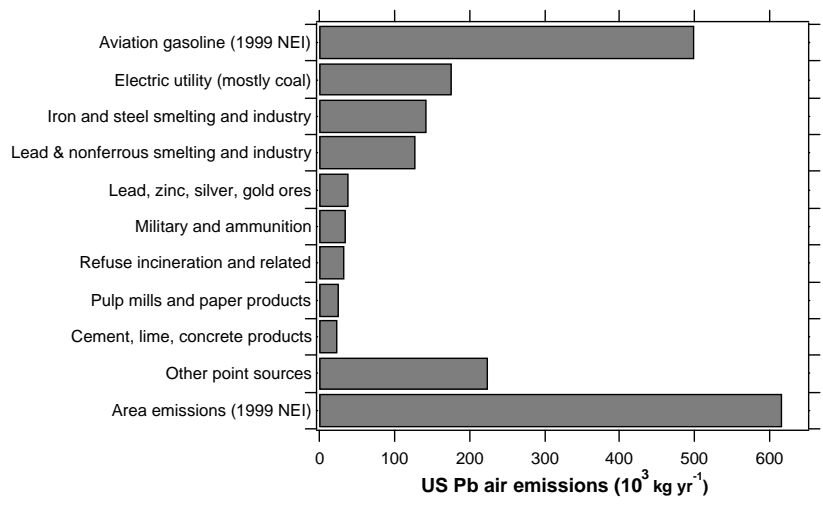

Fig. 1. United States National Emission Inventory (NEI) for Pb by category. The point sources are from the preliminary 2002 inventory.

Spain (Alvarez et al., 2004), with somewhat larger sizes recorded in Mumbai (Gokhale and Patil, 2004). A multistage impactor in Atlanta recorded the highest $\mathrm{Pb}$ concentrations on stage 8 , which samples below $100 \mathrm{~nm}$ (Solomon et al., 2003). An exception appears to be Zurich, where the majority of $\mathrm{Pb}$ was in particles larger than $2.5 \mu \mathrm{m}$ (Bukowiecki et al., 2005). An interesting progression was observed in the Los Angeles area. Lead was mostly in particles smaller than $350 \mathrm{~nm}$ in an industrial area in western Los Angeles but had a bimodal size distribution in Riverside, where there was a substantial amount in sizes larger than $1 \mu \mathrm{m}$ for which crustal elements predominated (Singh et al., 2002). This may represent resuspension of the lead deposited to the urban area over decades. The presence of $\mathrm{Pb}$ on sub-micrometer particles means that it can be efficiently inhaled.

The above size distributions were generally obtained with multi-stage impactors that respond to the aerodynamic diameter of the particles. For particles much larger than the mean free path in air, the aerodynamic diameter is proportional to the square root of the density. For particles much smaller than the mean free path in air, the vacuum aerodynamic diameter is proportional to density. As will be shown below, $\mathrm{Pb}$ in sub-micrometer particles is present both as small amounts on a large number of particles and a few particles rich in $\mathrm{Pb}$. Because of the high density of $\mathrm{Pb}$ and its compounds (usually $>6 \mathrm{~g} \mathrm{~cm}^{-3}$ ) as well as other metals usually associated with $\mathrm{Pb}$, those particles rich in $\mathrm{Pb}$ will usually have geometric diameters considerably smaller than their aerodynamic diameters.

Figure 1 shows some broad categories combined from more specific point sources in a preliminary 2002 United States Environmental Protection Agency (EPA) National Emissions Inventory. Area and aviation (non-road) emissions were taken from the 1999 county summary inventory because they were not yet available in the preliminary 2002 inventory. About the top 50 point sources were manually checked against the EPA Toxic Release Inventory. In many cases the
Toxic Release Inventory was more plausible. For example, the largest source in the preliminary 2002 point source inventory is a small foundry (90 employees) with listed air emissions of $115000 \mathrm{~kg}$ per year in the point source inventory and $5 \mathrm{~kg}$ per year in the Toxic Release Inventory. The largest point source in the United States, the Doe Run lead smelter, was listed as about $24 \mathrm{~kg}$ per year of airborne emissions in the point source inventory and over $45000 \mathrm{~kg}$ per year in the Toxic Release Inventory. Making corrections such as this resulted in a net reduction of about one third in total emissions. Many errors probably remain. In particular, large emissions near Cleveland come from area sources that are difficult to explain. It is also not clear why the major cities in California have much larger area emissions than other cities. Figure 2 shows the geographical distribution of sources in the United States.

According to the EPA inventories, aviation gasoline is the largest single source of airborne $\mathrm{Pb}$ emissions in the United States. Leaded aviation gasoline (as opposed to jet fuel) is used in small piston aircraft. A wide variety of other sources, many also from fuels, make significant contributions to airborne $\mathrm{Pb}$. Smelters, foundries, and coal combustion all also emit significant amounts of $\mathrm{Pb}$ and other trace metals. Combustion often generates small particles with relatively volatile metals partitioning to the small particles whereas refractory elements such as silicon partition to larger particles (Flagan and Taylor, 1981).

About $1 \times 10^{12} \mathrm{~kg}$ of coal were burned in the U.S. in 2004 (F. Freme, U.S. Energy Information Administration, U.S. Coal Supply and Demand: 2004 Review; http://tonto.eia.doe. gov/FTPROOT/features/feature04.pdf). Coal often contains 5 to 35 parts per million (ppm) of $\mathrm{Pb}$ (Raask, 1985; Linak and Wendt, 1993). Using $20 \mathrm{ppm}$, there is about 20000 tons per year of $\mathrm{Pb}$ in the coal burned in the United States. The EPA emissions inventory estimates that about $1 \%$ of this is emitted to the air. The volatility of $\mathrm{Pb}$ and its compounds such as $\mathrm{PbO}$ lead to its concentration in the sub-micrometer fraction of particles emitted from coal combustion and incineration (Davison et al., 1974; Linak and Wendt, 1993). Sub-micrometer particles are less efficiently removed by particulate emission control devices than larger particles. Hence a larger fraction could actually be emitted. Given the large amount of $\mathrm{Pb}$ in coal (Table 1), the airborne fraction of $\mathrm{Pb}$ from coal is crucial to the budget of atmospheric $\mathrm{Pb}$.

Lead is also emitted by combustion of liquid fuels containing trace amounts of $\mathrm{Pb}$. Such sources would be widely dispersed and produce fine particles. Table 1 shows an analysis of the $\mathrm{Pb}$ mass budget of several fuels in the United States. $\mathrm{The} \mathrm{Pb}$ content of fuels varies widely and for some fuels there are only one or two samples in the open literature. Trace metals are mostly in the asphaltenic fraction of crude oil (Dreyfus et al., 2005). The refining process concentrates metals into the heavy fractions such as heavy oil, asphalt, and coke, whereas gasoline and light fuels contain less $\mathrm{Pb}$ than crude oil. On a mass basis, therefore, the combustion of residual 


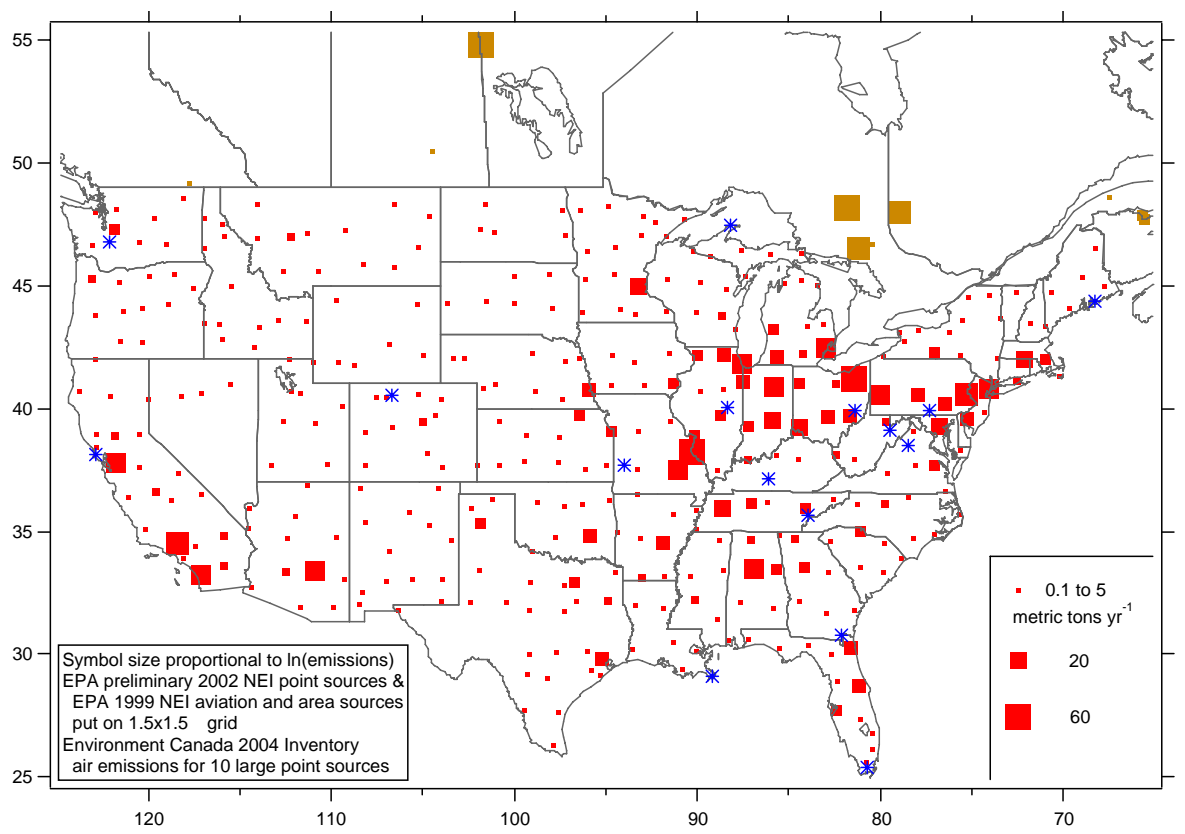

Fig. 2. Lead emissions from the EPA 1999 and 2002 National Emissions inventories and the 2004 Environment Canada National Pollutant Release Inventory on-line search. See text for modifications and error corrections to the inventories. To compensate for the different sizes of counties in the United States, county level data have been combined on a 1.5 by 1.5 degree grid. Each point is plotted at the weighted average position of the sources within the grid box. This helps properly position large point sources. Points less than $100 \mathrm{~kg} \mathrm{yr}^{-1} \mathrm{are} \mathrm{not} \mathrm{plotted.}$ These Canadian data do not include all the sources that are in the EPA database. Blue asterisks are selected IMPROVE network sites shown in Fig. 3.

oils may be a significant source of airborne $\mathrm{Pb}$, depending on the fraction that is emitted to the air. We were unable to locate firm numbers on this fraction. Used motor oil has a high enough $\mathrm{Pb}$ content to contribute to the overall amount of fuel $\mathrm{Pb}$ (Boughton and Horvath, 2004). A significant amount is burned in small space heaters with no emission controls.

The importance of industrial and coal combustion sources to present-day emissions of $\mathrm{Pb}$ has been shown by the correlation with other elements. Several other metals, including $\mathrm{Zn}$, are also present in trace amounts in coal and other fuels and have similar volatility and condensation processes in hot exhaust gases. Lead was correlated with $\mathrm{Zn}$ in the northern Pacific (Narita et al., 1999). In Detroit, $\mathrm{Pb}$ was correlated with As and Se, suggesting a fossil fuel combustion source (Utsunomiya et al., 2004).

Figure 3 shows selected data from the Interagency Monitoring of Protected Visual Environments (IMPROVE) network of sampling sites (Malm et al., 1994). Data through 2004 are available at http://vista.cira.colostate.edu/improve/ Data/data.htm. Absolute amounts of $\mathrm{Pb}$ are much higher in the eastern United States than the western United States. The geographic distribution, with elevated concentrations at sites in Illinois, Ohio, and Pennsylvania, is reasonably consistent with the emissions pattern (Fig. 2). As discussed later, IMPROVE sites in the western U.S. have a springtime maximum that is probably due to transport from Asia (see also K. Rahn's web site http://karws.gso.uri.edu/IMPROVE/ Pbpage.html). The eastern sites either have little seasonal pattern or a winter maximum. The origin of this winter maximum is not clear, especially since there is less general aviation in winter than in summer.

The lower panel of Fig. 3 shows the ratio of $\mathrm{Pb}$ to $\mathrm{Zn}$ at the same sites. The ratios for the central and eastern United States are quite consistently between 0.3 and 0.4 . For comparison, the $\mathrm{Pb} / \mathrm{Zn}$ ratio in aviation gasoline is very large, emissions from major smelters range between about 0.01 and 5 , in bulk coal the ratio is 0.1 to 0.75 (Raask, 1985; Linak and Wendt, 1993), and in used motor oil it is about 0.04 (Boughton and Horvath, 2004). The sites in the western United States show a range between the eastern U.S. and values near 0.7 . These higher ratios are discussed later in the context of transport from Asia.

\section{Methods}

This paper examines the distribution of $\mathrm{Pb}$ in single particles. The use of on-line laser ionization mass spectrometers provides high sensitivity along with data on hundreds of thousands of particles.

Most of the data shown here are from the Particle Analysis by Laser Mass Spectrometry (PALMS) instrument (Thomson et al., 2000). Air containing particles is brought through 
Table 1. Estimated United States mass budgets for $\mathrm{Pb}$ in selected fuels and crude oil.

\begin{tabular}{|c|c|c|c|c|c|c|}
\hline Fuel & $\begin{array}{l}2005 \text { U.S. con- } \\
\text { sumption } \\
(\mathrm{Tg})\end{array}$ & $\begin{array}{l}\text { Pb content } \\
\text { (ppm by mass) }\end{array}$ & $\begin{array}{l}\text { Total } \mathrm{Pb} \\
\left(10^{3} \mathrm{~kg} \mathrm{yr}^{-1}\right)\end{array}$ & $\begin{array}{l}\text { Airborne } \\
\text { fraction }\end{array}$ & $\begin{array}{l}\text { Airborne } \mathrm{Pb} \\
\left(10^{3} \mathrm{~kg} \mathrm{yr}^{-1}\right)\end{array}$ & References and notes \\
\hline Coal & 1020 & $5-35$ & 20000 & $\sim 0.01$ & $\sim 200$ & $\begin{array}{l}\text { Raask (1985); Linak and Wendt } \\
\text { (1993). Airborne fraction inferred } \\
\text { from Table 1.1-18 in EPA docu- } \\
\text { ment AP-42. }\end{array}$ \\
\hline Aviation gasoline & 0.8 & $\sim 750$ & 575 & $>0.75$ & 490 & \\
\hline Gasoline & 390 & 0.005 & 2 & 0.75 & 1.5 & $\begin{array}{l}\text { Heathcote et al. (2000) } \\
\text { A few samples in Iowa }\end{array}$ \\
\hline Jet fuel & 72 & $0.005-0.011$ & 0.6 & $1 ?$ & 0.6 & Shumway (2000) \\
\hline Distillate oil & 201 & $0.015-0.040$ & 4 & & & $\begin{array}{l}\text { Miller et al. (1996); Rising et } \\
\text { al. (2004) }\end{array}$ \\
\hline Residual oil & 50 & $2-21$ & $100->500$ & & & $\begin{array}{l}\text { Bratzel and Chakrabarti (1972); } \\
\text { Miller et al. (1996). } 21 \mathrm{ppm} \text { may } \\
\text { not be representative if crude oil } \\
\text { numbers are correct }\end{array}$ \\
\hline Used oil & 3 & $30-50$ & 100 & & & $\begin{array}{l}\text { Boughton and Horvath (2004); } \\
\text { Vermont (1994). }\end{array}$ \\
\hline Coke & 20 & $\geq$ residual oil? & $>80$ & & & $\begin{array}{l}\text { Much coke combustion probably } \\
\text { has emission controls. }\end{array}$ \\
\hline Crude oil & 744 & $0.032-0.97$ & $25-700$ & - & - & $\begin{array}{l}\text { Bratzel and Chakrabarti (1972); } \\
\text { Ali et al. (1983); Magaw et } \\
\text { al. (1999); Dreyfus et al. (2005). } \\
\text { Limited number of samples. }\end{array}$ \\
\hline
\end{tabular}

Fuel consumption figures from U.S. Department of Energy Energy Information Agency http://www.eia.doe.gov/emeu/aer/txt/ptb0511.html with unit conversion by author.

a vacuum interface. Particles that cross a continuous laser beam scatter light to trigger a pulsed $193 \mathrm{~nm}$ laser. The light pulse hits a particle and a complete mass spectrum is recorded using a time-of-flight mass spectrometer. Only particles larger than about $200 \mathrm{~nm}$ are detected. The most important consequence here is that fresh combustion particles are often not measured. Only positive ion spectra are considered in this paper since $\mathrm{Pb}$ produces only positive ions.

Data are shown from the PALMS instrument during four field campaigns. In 1999, the instrument was at the EPA Supersite in Atlanta. In 2002 and 2004, the instrument was flown on the NOAA P-3 aircraft. In spring 2002 the aircraft was based in Monterey, California and the data include flights both over the ocean and over land. One flight was dedicated to sampling the greater Los Angeles urban area. In summer 2004 the aircraft was based in Portsmouth, New Hampshire and flights were made over the eastern United States and Canada and nearby ocean. These flights included passes through the plumes from urban areas and major power plants. Some data are also included from descents into Houston made when the instrument was on the WB-57F aircraft in 2006. An overview of the overall particle chemistry observed during these missions is given in Murphy et al. (2006).
Between 1999 and 2004, a number of pertinent changes were made to the PALMS instrument. The instrument in Atlanta was a separate instrument from the aircraft version. It had a capillary inlet that was biased to sampling larger particles. The aircraft instrument has an additional turn in the drift tube of the mass spectrometer to fit it in the airplane (Thomson et al., 2000). Ion losses in this bend limit the sensitivity of the aircraft instrument to about a factor of two worse than the ground instrument. Furthermore, the instrument in the 2002 flights was tuned for minimum background instead of maximum sensitivity, with an additional ion loss of perhaps a factor of five. The 2004 and later data include the aerodynamic diameter of most of the particles. These aerodynamic diameters are measured at a pressure where the mean free path is larger than the particles, leading to a linear rather than square root dependence on particle density.

The Aerosol Time of Flight Mass Spectrometer (ATOFMS) is a commercially available instrument (Model 3800, TSI, Shoreview, MN) described by Gard et al. (1997). The operating principles of this instrument are much the same as for PALMS. Particles and gas enter the instrument through an aerodynamic lens optimized for diameters between 300 and $1000 \mathrm{~nm}$. Gas-phase molecules 
are then removed via differential pumping stages. Particle transmission falls off to either side of these limits such that no particles were observed smaller than $250 \mathrm{~nm}$ or larger than $2500 \mathrm{~nm}$ during these studies. Particles are detected and optically sized using dual continuous lasers. Unlike the PALMS instrument, aerosol ablation and ionization is accomplished with a pulsed $266 \mathrm{~nm}$ laser. Dual time-of-flight tubes allow for both positive and negative mass spectra being recorded for each particle. While $\mathrm{Pb}$ is only observed as a positive ion, associations with negative ions can thus be made.

An ATOFMS was deployed to the Jungfraujoch Research Station for the first two weeks of March 2006 as part of the Fifth Cloud and Aerosol Characterization Experiment in the Free Troposphere (CLACE 5). Located in the Swiss Alps at $3580 \mathrm{~m}$ above sea level, the Jungfraujoch allows access to mid-tropospheric air with minimal local aerosol sources (Baltensperger et al., 1997). As such, the data presented here are probably most comparable to the PALMS aircraft data. The focus of the deployment of the ATOFMS during CLACE 5 was the characterization of the chemical composition of ice nuclei within mixed-phase clouds. The majority of observation time was therefore spent analyzing cloud ice residue. Every two hours from 08:00 through 18:00 local time several thousand unactivated particles were analyzed for comparison to the subset that nucleated ice. An "interstitial inlet" with a $2.5 \mu \mathrm{m}$ cutpoint was used for sampling. When clouds were not present the background aerosol was sampled in the same manner and through the same inlet. The data described here are restricted to unactivated particles during cloud free periods.

The Rapid Single particle Mass Spectrometer (RSMS) performs size-selective single particle analysis between about 30 and $1200 \mathrm{~nm}$ diameter. Particles are drawn into the instrument through a size selective inlet (Mallina et al., 2000). The vacuum aerodynamic diameter of particles transmitted to the mass spectrometer source region is determined by the pressure at a critical orifice. The pressure is set by a flow-limiting orifice located upstream of the critical orifice. A valve switches between a bank of orifices to allow rapid changing of the selected particle size. Single particle measurements at the selected size are performed by free-firing a pulsed $193 \mathrm{~nm}$ laser beam through the source region.

Since the particle size is actively selected and the laser is free-fired, single particle mass spectra can be obtained for particle sizes below the minimum size that can be detected by light scattering. The disadvantage, though, is that the analysis rate for particles large enough to be detected by light scattering is lower for RSMS than PALMS or the ATOFMS. To help compensate for the low analysis rate, the mass analyzer in the RSMS instrument contains an elongated source region, linear flight tube and collinear geometry between the particle and laser beams to maximize the interaction region between the laser and particle beams. The linear flight tube yields lower mass resolution than a reflectron design. Further
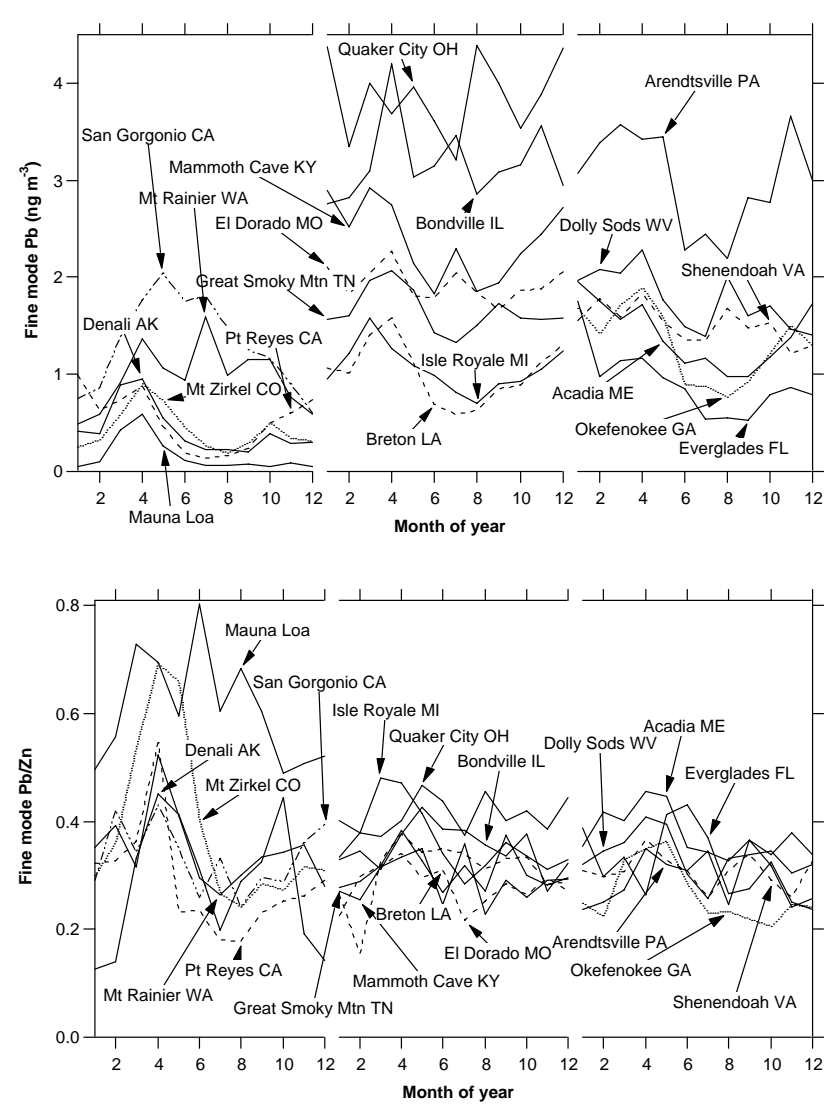

Fig. 3. Seasonal patterns for fine mode $\mathrm{Pb}$ and $\mathrm{Zn}$ at several IMPROVE sampling sites, roughly grouped by western, central, and eastern United States. Dashed lines are only to distinguish between lines on the graph. These are averages for 1999 to 2004, although some of these stations have shorter records.

discussion of particle analysis by RSMS is given by Lake et al. (2003).

Data from five RSMS measurement campaigns are discussed including August 1999 in Atlanta, Georgia (Rhoads et al., 2003), August-September 2000 in Houston, Texas (Phares et al., 2003), September 2002-August 2003 in Pittsburgh, Pennsylvania (Bein et al., 2005), March-December 2003 in Baltimore, Maryland (Tolocka et al., 2005), and May 2005-February 2006 in Wilmington, Delaware. Single particle measurements were supplemented at each of the measurement sites with concurrent meteorology data and various gas phase and particulate concentrations.

Although isotopic information on $\mathrm{Pb}$ would be useful in constraining sources, the time-of-flight mass spectrometers used in all three instruments are not designed for isotopic analysis. Space charge effects and the high energy imparted by laser ionization mean that the $\mathrm{Pb}$ peaks are often not sufficiently well resolved for the very accurate peak integrations required for isotopic analysis. 

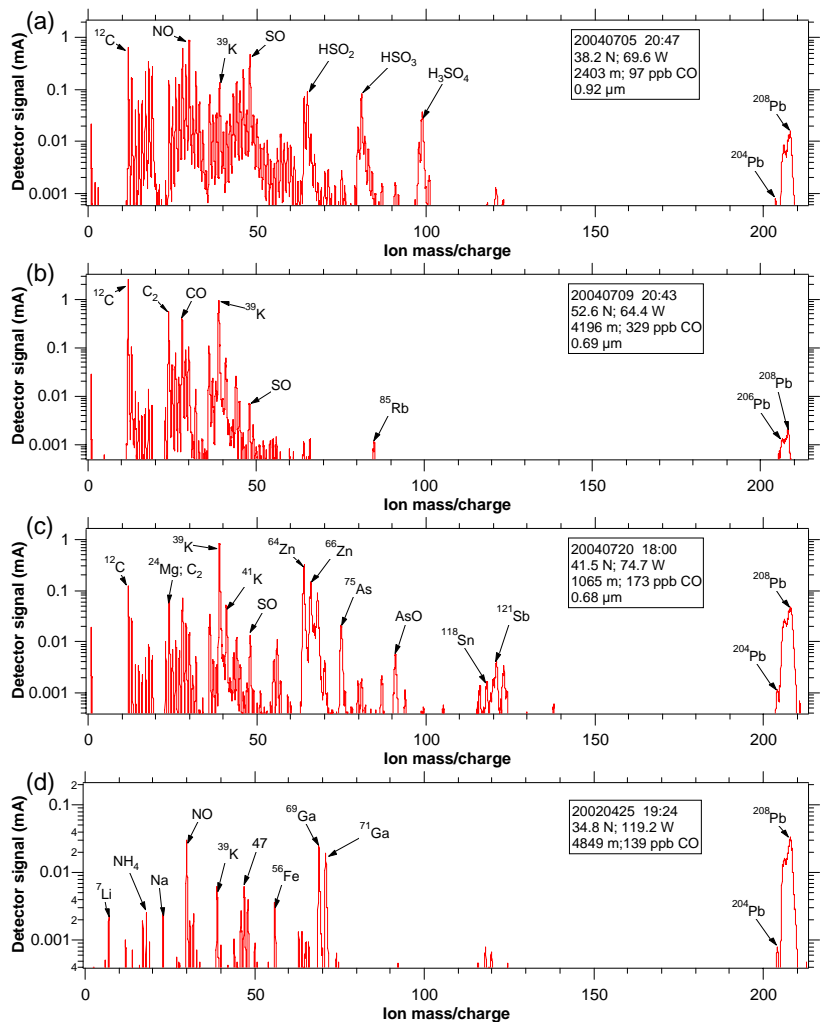

Fig. 4. Examples of mass spectra of single particles containing $\mathrm{Pb}$. (a) A common mixed sulfate-organic particle. (b) A particle in a biomass burning plume over Canada. (c) A particle with other metals. The association of $\mathrm{Pb}$ with one or more of $\mathrm{K}, \mathrm{Zn}, \mathrm{Sn}$, and $\mathrm{Sb}$ was common. (d) A Pb-Ga particle from trans-Pacific flow west of California. Gallium is quite rare in atmospheric particles, but the isotopic pattern is definitive.

\section{Results}

\subsection{PALMS}

Lead was present both as a small signal in the mass spectra of many particles and as a large signal in a few mass spectra. Figure 4 shows some mass spectra of particles with $\mathrm{Pb}$. Besides the $\mathrm{Mg}, \mathrm{K}, \mathrm{Zn}, \mathrm{As}$, Sn, and $\mathrm{Sb}$ shown (Fig. 4c), Cu and $\mathrm{Fe}$ were also common in $\mathrm{Pb}$-rich particles, with occasional $\mathrm{Li}, \mathrm{Mn}$, and $\mathrm{Ba}$. The gallium shown in Fig. 4d was found in 7 spectra, of which 6 were west of or near the California coast.

Figure 5 presents histograms of the frequency of different size peaks at a mass to charge ratio of 208 , which is almost always ${ }^{208} \mathrm{~Pb}$. There are few other ions with the same masses as $\mathrm{Pb}$. Because the $\mathrm{Pb}$ peaks at mass to charge ratios of 206 and 207 were not always well resolved, only mass 208 is used in Fig. 5 as a measure of $\mathrm{Pb}$. Except for very small $\mathrm{Pb}$ signals for which the frequency depends on the varying detection limit, the histograms for Atlanta and aircraft flights over the eastern U.S. are very similar. This is consistent with a regional source in Atlanta without any obvious dependence on wind direction (Lee et al., 2002). The data for the western U.S. show relatively higher concentrations for particles with moderate amounts of $\mathrm{Pb}$.

The data sorted by portion of the western U.S. (Fig. 5b) provide some insight into the relatively higher concentrations. The Los Angeles area had slightly less frequent $\mathrm{Pb}$ signals when expressed as a fraction of the number of particles. The aerosol number concentration in Los Angeles is much larger than offshore, so there was more $\mathrm{Pb}$ on an $\mathrm{ab}$ solute basis. The relative concentrations were lower because of dilution by ammonium nitrate and other abundant species. Figure $5 \mathrm{~b}$ also shows data from 2004 sorted by vacuum aerodynamic diameter. The larger particles were more likely to have large $\mathrm{Pb}$ signals. Note that a particle large enough to be detected optically (larger than 200 or $300 \mathrm{~nm}$ ) with a high lead content is likely to have a vacuum aerodynamic diameter greater than $1 \mu \mathrm{m}$. There was almost no size dependence to the frequency of particles with smaller $\mathrm{Pb}$ content.

Figure 6 shows the geographic distribution of the average ${ }^{208} \mathrm{~Pb}$ signal and the frequency with which ${ }^{208} \mathrm{~Pb}$ was more than $0.03 \%$ (the limit of consistent detection) of the ion current in each mass spectrum. The average signal is affected by those particles with high $\mathrm{Pb}$ content, such as $4 \mathrm{c}$ and $4 \mathrm{~d}$. In interpreting the average ${ }^{208} \mathrm{~Pb}$ signal it must be remembered that this is a relative measure. Considering the total amount of aerosol present, the absolute concentrations of $\mathrm{Pb}$ are higher in the northeastern United States than off the California coast.

The maximum off California is discussed below under Asian transport. The other maximum in the average $\mathrm{Pb}$ signal was in the Ohio River valley. The airplane spent some time there intentionally flying through power plant plumes. However, on a fine scale the average $\mathrm{Pb}$ in the mass spectra were only weakly positively correlated with gas phase measurements of $\mathrm{SO}_{2}$ and the frequency of $\mathrm{Pb}$ was uncorrelated with $\mathrm{SO}_{2}$, so it is unclear if this maximum is due to power plant plumes or other emissions in this industrialized region. Many of the Pb-rich particles also contained $\mathrm{Zn}$, as in Fig. 4c.

The frequency of particles with measurable $\mathrm{Pb}$ was more uniform than the average signal. About $10 \%$ of all particles sampled above North America contained measurable $\mathrm{Pb}$. Since many mass spectra had $\mathrm{Pb}$ signals near the detection limit (Fig. 4a), it is likely that a better detection limit would show an even higher frequency of $\mathrm{Pb}$. The overall frequency for the aircraft data is consistent with that reported for PALMS data in Atlanta (Lee et al., 2002). The somewhat higher frequencies along the North and South Carolina coasts are from one flight. For that flight leg, the surface influence parameter calculated by the FLEXPART back trajectory model (Stohl et al., 2005) shows a significant contribution from large source regions in Arizona, Arkansas and southern Illinois and Missouri (Fig. 2 and http://www.atmos-chem-phys.net/7/3195/2007/ acp-7-3195-2007-supplement.pdf). 

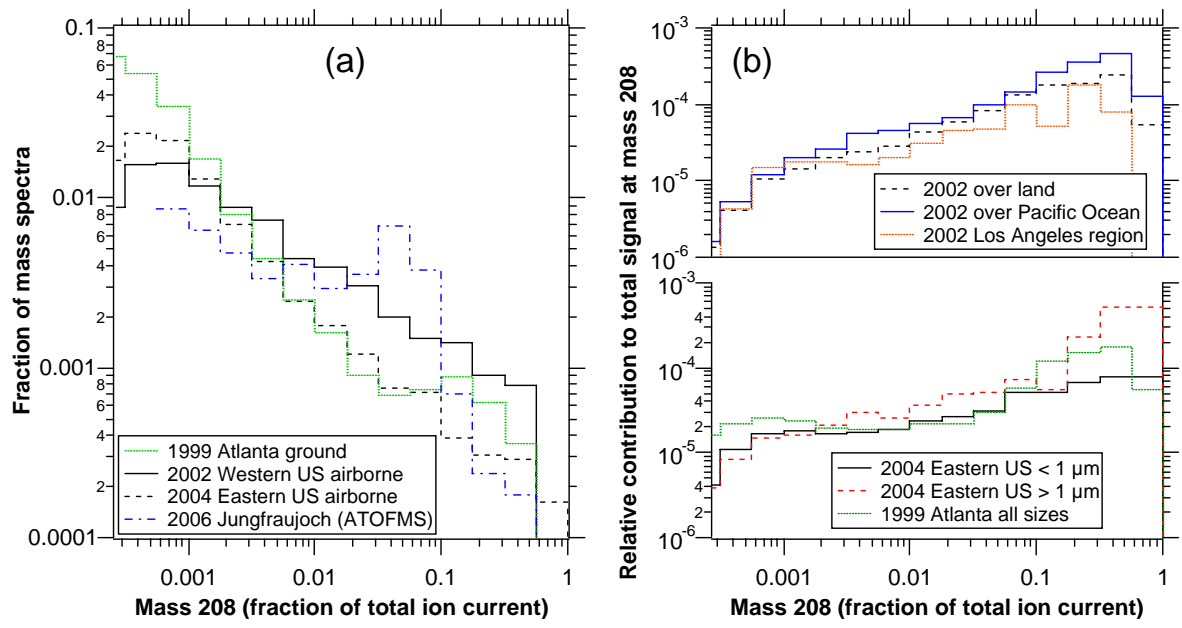

Fig. 5. Histograms of the size of ${ }^{208} \mathrm{~Pb}$ peak in individual particles. In (a), the deviations below a mass 208 fraction of 0.001 are mostly due to variations in signal-to-noise. Such small peaks often fell below the detection limit. The instrument in Atlanta had the largest absolute signals and that in 2002 the smallest. Panel (b) shows weighted histograms, or the histogram with the frequency multiplied by the midpoint of each bin. This shows the relative contribution to the average total signal. The data are also further broken into regions or sizes. The size cut for the 2004 data is by vacuum aerodynamic diameter. All data have been restricted to relative humidity less than $98 \%$ and the airborne data are restricted to altitudes above $150 \mathrm{~m}$ to exclude final approaches to airports and some flight segments in the marine boundary layer. See Fig. 6 for more detailed locations.

The vertical profiles of the average ${ }^{208} \mathrm{~Pb}$ signal had little structure (Fig. 7). The decrease in the 2002 data near the surface is caused almost entirely by flight legs in the marine boundary layer west of California. Sea salt particles in the marine boundary layer contained almost no $\mathrm{Pb}$, reducing its relative concentration. The peak in the 2002 data at just under $5 \mathrm{~km}$ is due to the influence of the flight leg that produced the large point on Fig. 6 off the coast of California near $36^{\circ} \mathrm{N}$. Vertical profiles of the frequency of particles containing $\mathrm{Pb}$ also had little structure.

\subsection{Results: ATOFMS}

During the CLACE 5 campaign conducted at the Jungfraujoch Research Station, about $5 \%$ of the analyzed aerosol particles were identified as containing lead. Lead was identified if the signal at the dominant isotope, ${ }^{208} \mathrm{~Pb}$, was larger than an arbitrary threshold set at twice the level of the spectra noise. This threshold value represented about $0.05 \%$ of the total signal in an average spectrum. At this level only the ${ }^{208} \mathrm{~Pb}$ isotope was identifiable. Other isotopes $\left({ }^{206} \mathrm{~Pb}\right.$ and ${ }^{207} \mathrm{~Pb}$ at $24.1 \%$ and $22.1 \%$, respectively) became apparent when the relative ${ }^{208} \mathrm{~Pb}$ signal was greater than about $0.25 \%$. In no case was the ${ }^{204} \mathrm{~Pb}$ isotope $(1.4 \%)$ clearly identified. As is the case for the PALMS measurements, the $5 \%$ of spectra with $\mathrm{Pb}$ likely represents a lower limit of the fraction of particles that contained lead since detection appears limited by signal.

Of the particles that had detectable lead, $25 \%$ had a relative signal greater than $5 \%$ of the total spectrum. A typical example of such a "high lead" particle is shown in Fig. 8a. Whereas spectra for typical ambient aerosols predominantly contained sulfate and organics fragments, $\mathrm{Pb}$-rich particles always contained one or more of the following positive ions: $\mathrm{Na}^{+}, \mathrm{Mg}^{+}, \mathrm{Al}^{+}, \mathrm{K}^{+}, \mathrm{Fe}^{+}, \mathrm{Zn}^{+}, \mathrm{Mo}^{+}, \mathrm{Ag}^{+}, \mathrm{Ba}^{+}$. These ions were otherwise only observed in $<5 \%$ of spectra without lead, with the exception of potassium which is commonly associated with biomass burning and was found in about $40 \%$ of the positive spectra (Hudson et al., 2004). Sulfate fragments were present in $99 \%$ of the negative spectra associated with high $\mathrm{Pb}$ particles and $50 \%$ also contained $\mathrm{NO}_{2}^{-}$and $\mathrm{NO}_{3}^{-}$. Approximately $80 \%$ contained positive and/or negative polarity organic fragments. The average aerodynamic diameter of the $\mathrm{Pb}$-rich particles was larger than the background aerosol, which had a peak at $350 \mathrm{~nm}$. Instead, the size distribution for high lead particles peaked at $500 \mathrm{~nm}$ and none were observed with a diameter less than $300 \mathrm{~nm}$. If the $\mathrm{Pb}$-rich particles had high density then this means that most probable size was near or below the size limit of detection in ATOFMS.

The spectra of "low lead" particles, one of which is shown in Fig. 8b, were much more varied. About $40 \%$ contained the aforementioned metals as well as $\mathrm{Ga}^{+}, \mathrm{Ge}^{+}$and $\mathrm{Sn}^{+}$. The remainder appeared in spectra that were otherwise indistinguishable from those typically observed (i.e., sulfate and organics fragments commonly with $\mathrm{K}^{+}$and nitrates). In addition, the aerodynamic diameters of the low lead particles were indistinguishable from that of the background aerosol. Lead was found down to the smallest detected particles, about $250 \mathrm{~nm}$. It is worth mentioning that $\mathrm{Pb}$ was not 

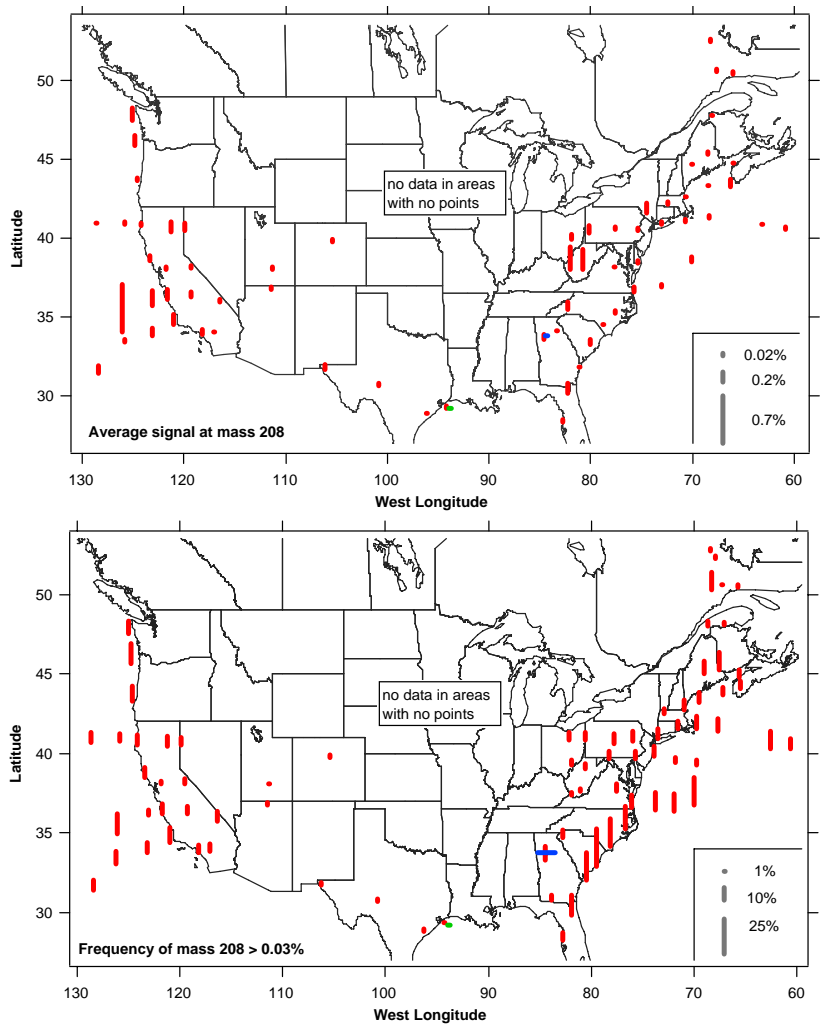

Fig. 6. Geographical distribution of the average PALMS signal at mass 208 , which is almost always ${ }^{208} \mathrm{~Pb}$, along with the frequency of that peak in single particles. The data were binned into 2 to 2.5 degree boxes with the points plotted where taken - if the aircraft only flew through a corner of a grid box the point is plotted at the corner. There are a few more points plotted in the lower panel because at least 150 mass spectra in a grid box were required to define a frequency whereas at least 400 were required for the average, which can be affected by one particle with a large $\mathrm{Pb}$ signal. Mass spectra with a signal to noise less than about 1000 were not included in the frequency calculation. Aircraft data are from above $150 \mathrm{~m}$ altitude and less than $98 \%$ relative humidity. The horizontal bars near Atlanta and Houston are from the 1999 Supersite and 2006 NASA WB-57F descents, respectively.

found on any of the elemental carbon particles, about $4 \%$ of the total number.

\subsection{Results: RSMS}

Single particle measurements made by the RSMS instrument in five eastern U.S. cities show that $\mathrm{Pb}$ is ubiquitous in the urban environment and provide insight into possible sources. These measurements were made across a size range of about 30 to $1200 \mathrm{~nm}$ in vacuum aerodynamic diameter. The size range differed slightly for the different measurement sites.

The fraction of particles analyzed by RSMS that contained measurable $\mathrm{Pb}$ ranged from about $0.5 \%$ in Atlanta (Rhoads et al., 2003) and Houston (Phares et al., 2003) to greater than

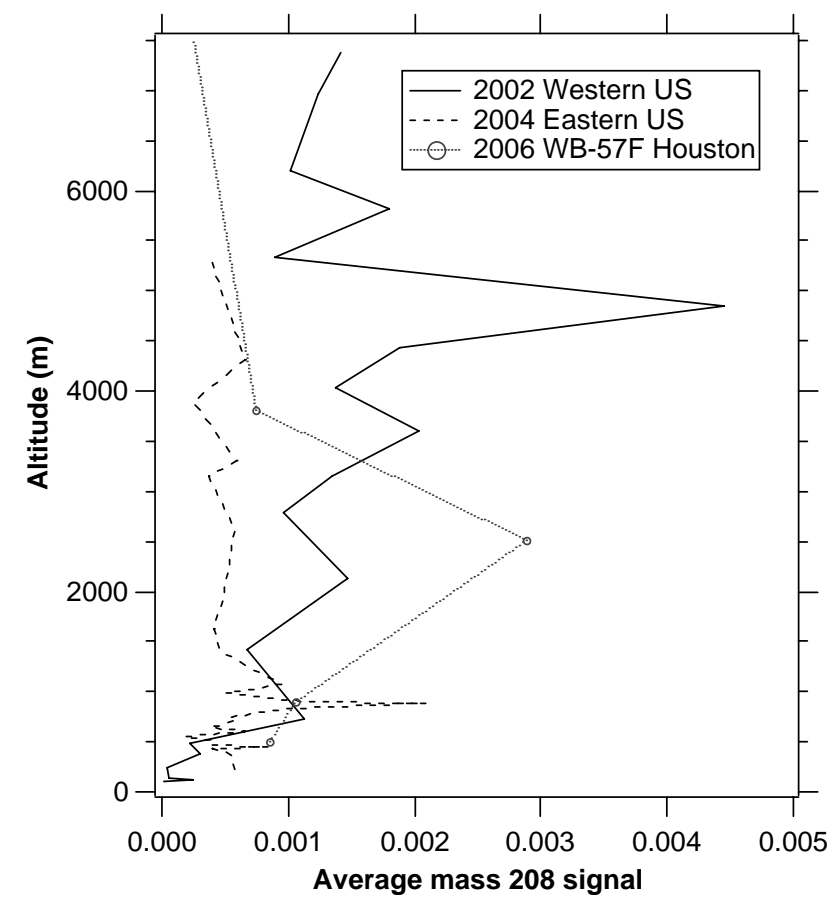

Fig. 7. Average vertical profiles of the fraction of total ions at mass 208 for three missions. The only statistically significant variations are the decrease near the surface and the peak in the 2002 profile at $5 \mathrm{~km}$.

3\% in Pittsburgh (Bein et al., 2005) and Baltimore (Tolocka et al., 2005). Relative to the PALMS and ATOFMS measurements above, the number of particles analyzed with RSMS that contain a detectable amount of $\mathrm{Pb}$ is likely to be smaller because the dynamic range of signal intensity measurement is lower for RSMS than PALMS. Therefore, it is probable that trace levels of $\mathrm{Pb}$ in many particles were not detected with RSMS. In the RSMS measurements, particles containing $\mathrm{Pb}$ were often detected in "bursts" that often correlated strongly with wind direction and the presence of other metals, consistent with point source plumes that passed over the measurement site. Plots of $\mathrm{dN} / \mathrm{d} \log \mathrm{d}_{v a}$ vs. $d_{v a}$ typically reached a maximum around $200 \mathrm{~nm}$ with a peak value of 10 $100 \mathrm{~cm}^{-3} \mathrm{~Pb}$-containing particles averaged over an extended period of time (Tolocka et al., 2004).

An example of $\mathrm{Pb}$ in urban aerosol is shown in Fig. 9 for RSMS measurements in 2005 at Wilmington, Delaware. Two main classes of particles containing $\mathrm{Pb}$ were found in the dataset. The first, shown in Fig. 9a, shows $\mathrm{K}$ and $\mathrm{Pb}$ as dominant features in the mass spectrum. Other ions suggest the presence of $\mathrm{Na}$, elemental carbon, organic carbon and possibly amines. This particle class encompassed about $1 \%$ of the particles analyzed. The number concentration reached a maximum around $200 \mathrm{~nm}$ although many particles were observed at the smallest size analyzed in this experiment $(50 \mathrm{~nm})$. It should be noted that these are vacuum 

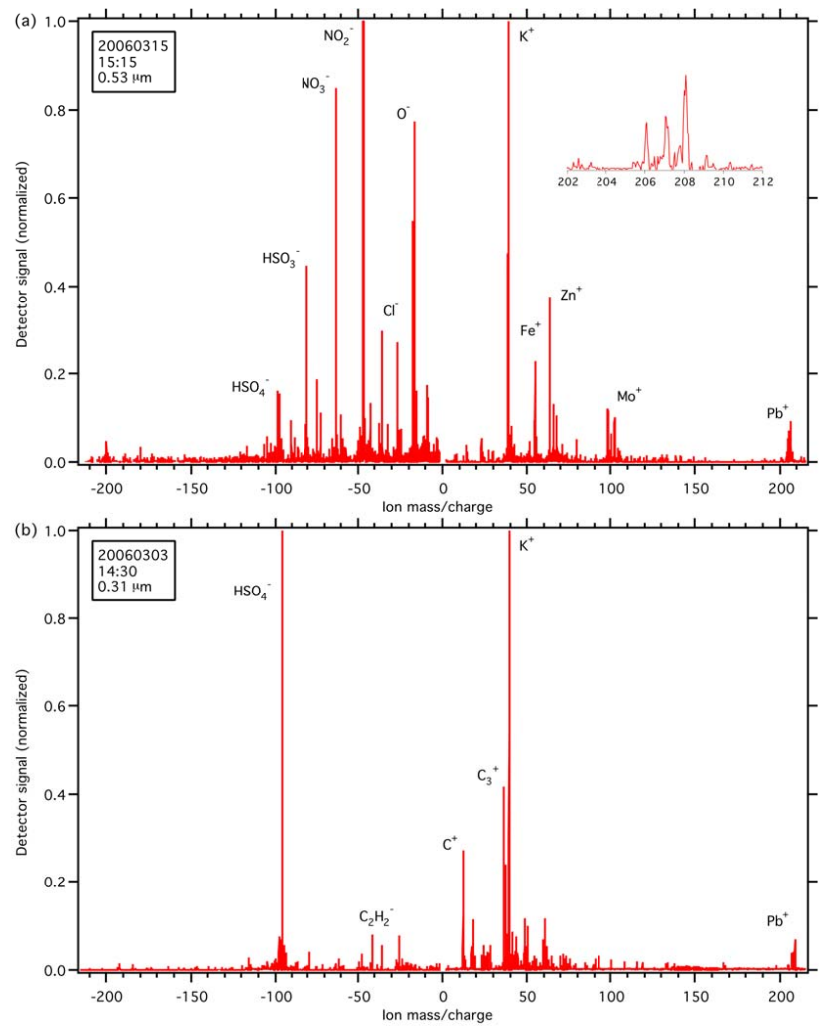

Fig. 8. Examples of ATOFMS mass spectra of single particles containing lead at the Jungfraujoch Research Station. (a) A particle with $>5 \%$ of the relative signal from lead and containing several commonly associated metals. The negative spectrum contains fragments from sulfates and nitrates as well as $\mathrm{Cl}^{-}$. The inset shows the clear isotopic distribution of lead. (b) A particle with $\mathrm{K}^{+}$and sulfate and organic fragments. Other than a lead peak with $<1 \%$ of the relative signal, this particle is indistinguishable from background aerosols of probable biomass origin with added sulfate.

aerodynamic diameters and the physical diameters are likely to be a factor of 4 or more smaller depending on composition and density. This means that most of the Pb-rich particles measured by RSMS would be too small for detection by PALMS or ATOFMS. The wind rose plot for this particle class is diffuse, which suggests multiple sources. In general, industrial sites (steel processing, manufacturing, power generation, refining) are located from the northeast to the southwest of the site, while residential and traffic (Interstate 95) sources are prevalent in the north and west.

A second, minor class is shown in Fig. 9b, which encompassed about $0.1 \%$ of the particles analyzed. Dominant features in the mass spectrum include $\mathrm{Na}, \mathrm{K}, \mathrm{Zn}$, and $\mathrm{Pb}$ with smaller signals from $\mathrm{Fe}$, elemental carbon and organic carbon. As above, the number concentration reached a maximum around $200 \mathrm{~nm}$, although the size distribution was skewed toward larger particles suggesting that the tail of a coarse mode was also observed. The wind rose plot
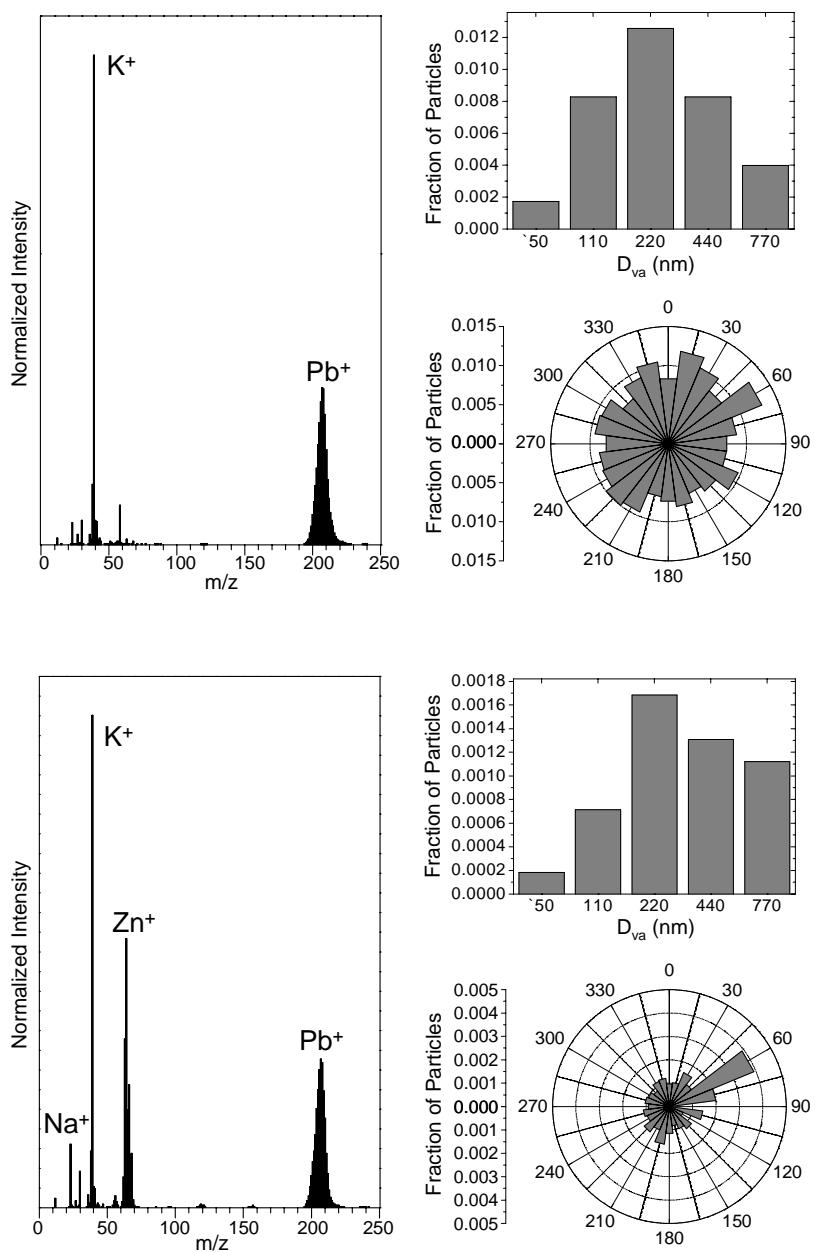

Fig. 9. Major particle classes in Wilmington, Delaware that contain $\mathrm{Pb}$ : a $\mathrm{K}$ and $\mathrm{Pb}$ class and a $\mathrm{Na}, \mathrm{K}, \mathrm{Zn}$, and $\mathrm{Pb}$ class. The class the lower panel appears to be emitted from a steel processing facility. Stack sampling at the facility confirms the source of these particles.

shows a clear feature at $60^{\circ}$, which is the direction of a steel manufacturing and processing facility located about $10 \mathrm{~km}$ from the measurement site. In a separate experiment, aerosol was sampled directly from the emission stack of this facility and analyzed by RSMS. About $4 \%$ of the particles in the stack sample gave the same mass spectrum as that in Fig. 9b. (The remaining particle spectra, perhaps formed by hot vapor condensation during the sampling process, were organic/elemental carbon in character and contained no significant metals.) The stack measurements confirm the interpretation of the ambient data in Fig. 9b that these particles were emitted from the steel facility.

The data in Fig. 9 are also characteristic of measurements in the other four cities. Particles containing $\mathrm{Pb}$ almost always contained $\mathrm{K}$ and often $\mathrm{Zn}$ as well. Many of these particles were internally mixed, showing mass spectral signatures for organic carbon, nitrate, and/or sulfate. The size distribution 


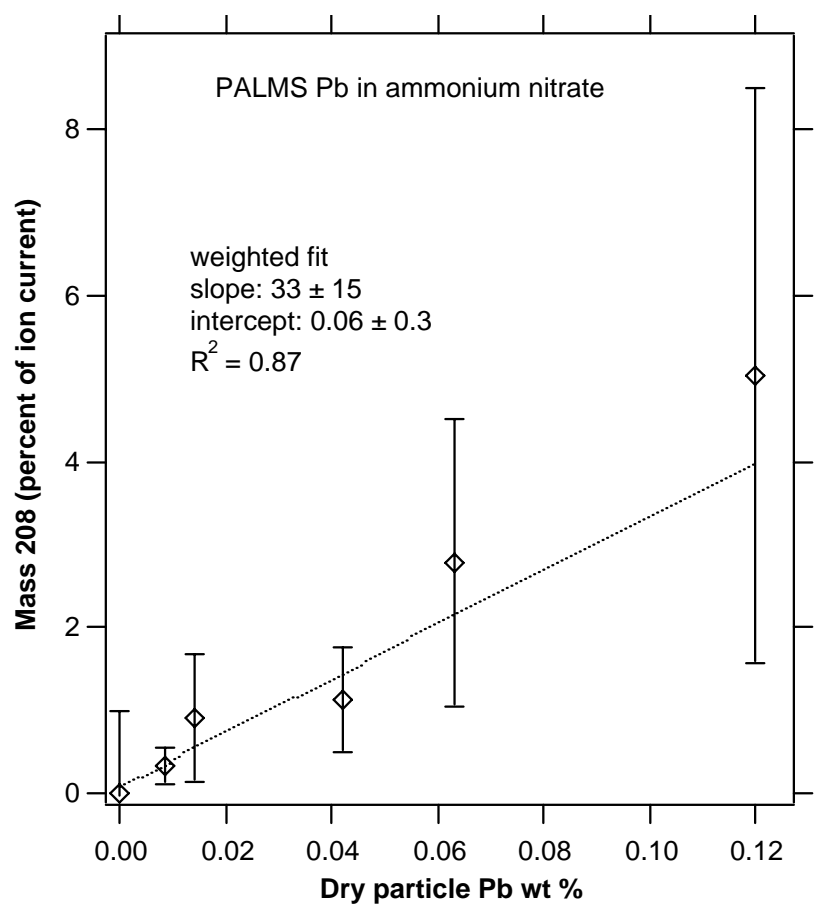

Fig. 10. Laboratory calibration of $\mathrm{Pb}$ in ammonium nitrate particles generated by nebulizing a solution.

usually peaked around $200 \mathrm{~nm}$, although the number concentration remained large at smaller sizes (Tolocka et al., 2004). A significant wind directionality was also commonly observed for $\mathrm{Pb}$ particles containing a large combination of metals. In Pittsburgh, a particle class containing $\mathrm{Na}, \mathrm{K}, \mathrm{Zn}$ and $\mathrm{Pb}$, though in different proportions from those in Fig. $9 \mathrm{~b}$, was attributed to a zinc processing facility (Bein et al., 2005). A transient plume of particles containing $\mathrm{Na}, \mathrm{Si}, \mathrm{K}, \mathrm{Ca}, \mathrm{Fe}$, $\mathrm{Ga}$ and $\mathrm{Pb}$ was attributed to coal combustion (Bein et al., 2006). Mass concentrations of $\mathrm{Pb}$ obtained from MOUDI samples at the Pittsburgh site showed a maximum around $200 \mathrm{~nm}$ along with evidence for the tail of a coarse mode near $1000 \mathrm{~nm}$. The coarse mode appeared to be dominated by multi-metal classes, while the fine mode contained mostly particles having $\mathrm{K}, \mathrm{Pb}$ and secondary aerosol components as the dominant species. Reconciliation of RSMS data with mass concentrations from MOUDI samples suggest density and shape factors of $3.0 \mathrm{~g} \mathrm{~cm}^{-3}$ and 1.4 for $\mathrm{Na}-\mathrm{K}-\mathrm{Zn}-\mathrm{Pb}$ particles, and $3.9 \mathrm{~g} \mathrm{~cm}^{-3}$ and 1.5 for $\mathrm{Na}-\mathrm{Si}-\mathrm{K}-\mathrm{Ca}-\mathrm{Fe}-\mathrm{Ga}-\mathrm{Pb}$ particles. During plume events, the $24 \mathrm{~h}$ average $\mathrm{Pb}$ concentration ( $\mathrm{PM}_{1.2}$ ) could reach $0.5 \mu \mathrm{g} \mathrm{m}^{-3}$ (Bein et al., 2006).

\section{Discussion}

\subsection{Calibration}

It is difficult to convert the ion fractions shown in the preceding figures into absolute concentrations of $\mathrm{Pb}$. The conversion depends on both the ionization efficiency of $\mathrm{Pb}$ and the size range and sampling biases of the mass spectrometer. Figure 10 shows a PALMS calibration for $\mathrm{Pb}$ in ammonium nitrate particles that also contained trace amounts of added $\mathrm{Fe}$. The linearity is good for laser ionization. The slope of about 33 shows that PALMS is much more sensitive to $\mathrm{Pb}$ than ammonium nitrate. The high sensitivity to $\mathrm{Pb}$ is similar to results for other metals such as Fe in sulfuric acid (Cziczo et al., 2001). Mixed solutions with both $\mathrm{Pb}$ and $\mathrm{Fe}$ in ammonium nitrate showed similar sensitivities for $\mathrm{Pb}$ and $\mathrm{Fe}$.

Separate calibrations for $\mathrm{Pb}$ were performed for ATOFMS. The ATOFMS mass scale was calibrated on a daily basis during CLACE 5 using a standard solution of 900 micrograms per milliliter of six components $(\mathrm{Li}, \mathrm{Na}, \mathrm{K}, \mathrm{V}, \mathrm{Ba}$, and $\mathrm{Pb})$ in a $5 \%$ solution of $\mathrm{HNO}_{3}$ balanced by distilled, deionized water (i.e., $\sim 0.02 \mathrm{wt} \%$ lead with respect to $\mathrm{HNO}_{3}$ ). Aerosols atomized from this solution were passed through a diffusion dryer at $30 \%$ relative humidity and size selected with a differential mobility analyzer at $0.5 \mu \mathrm{m}$. The dominant positive ions were $\mathrm{K}, \mathrm{V}$, and $\mathrm{VO}$, each of which had relative peak areas of $10-20 \%$. Li and $\mathrm{Na}$ ions had relative areas on the order of $5-10 \%$ followed by $\mathrm{Ba}$ and $\mathrm{BaO}$ with approximately $1 \%$. Lead ions were observed in about half of spectra with an average relative area of $0.5 \%$, giving a relative sensitivity of $\mathrm{Pb}$ to nitric acid of about 12. This is a factor of 3 lower than found for lead in ammonium nitrate for PALMS, probably because the easily ionized alkali metals in the ATOFMS calibration mixture reduce the relative contribution from $\mathrm{Pb}$ as well as the different ionization laser wavelength.

It should not be assumed that the average $\mathrm{Pb}$ signals shown, for example, in Fig. 6a should be divided by the PALMS calibration slope of about 33 to obtain $\mathrm{Pb}$ mass fractions. First, the relative sensitivity to ammonium nitrate is a measure not only of how easily $\mathrm{Pb}$ is ionized but how difficult it is to ionize ammonium nitrate. A $\mathrm{Pb}$ calibration in a more easily ionized matrix such as sea salt would have a much smaller slope. Many particles with $\mathrm{Pb}$ also contained $\mathrm{K}$, which could considerably change the relative sensitivity. A relative sensitivity for realistic atmospheric particles could be much lower, perhaps 5 to 10 .

Second, a pure $\mathrm{Pb}$ particle cannot produce more than $100 \% \mathrm{~Pb}$ ions. A simple algebraic expression with the desired asymptotes of a relative sensitivity of $S$ at low concentration and $100 \%$ ion yield for a pure substance is

$C=x /(x+S(1-x))$

where $x$ is an ion fraction, $C$ is the fractional concentration, and $S$ is the relative sensitivity. For $S$ greater than 1, this 
has the effect of stretching the $\mathrm{x}$-axis on a histogram such as Fig. 5.

\subsection{Contamination}

Contamination is always a concern when measuring trace metals. For example, sample contamination caused early work to overestimate $\mathrm{Pb}$ in water samples (Nriagu et al., 1993). There are several reasons why the data here should be representative of the actual distribution of $\mathrm{Pb}$ on particles. Laser ionization done in vacuum inherently has essentially zero background for $\mathrm{Pb}$. The only concern is if $\mathrm{Pb}$ particles are being generated in the inlet or if ambient particles are acquiring $\mathrm{Pb}$ by bouncing off an inlet wall. However, laboratory particles without added $\mathrm{Pb}$ do not give any $\mathrm{Pb}$ signal, showing that the vacuum inlet is not contributing any $\mathrm{Pb}$ signal. The intercept on Fig. 11 also shows that fresh biomass burning particles are measured with essentially zero $\mathrm{Pb}$. There are no $\mathrm{Pb}$-containing materials such as solder in any of inlets for the data in this paper. There are four completely independent inlets: two for PALMS, since the inlet in Atlanta shared no common components with the aircraft inlet, the inlet for the ATOFMS, and the inlet for RSMS. Data within clouds were excluded because cloud droplets and ice at aircraft velocities can abrade inlet walls. Finally, the fact that the $\mathrm{Pb}$ signal drops both in the marine boundary layer (Fig. 7) and the stratosphere (not shown) indicates that the $\mathrm{Pb}$ measured at intermediate altitudes is real.

\subsection{Biomass burning plumes}

Besides the wide geographic and altitude distribution of $\mathrm{Pb}$, it was also present on many types of particles. One type of particular interest is biomass burning particles. On 9 July and 27 July 2004, the P-3 aircraft sampled forest fire plumes from fires in northwestern Canada and eastern Alaska (de Gouw et al., 2006). The plumes, especially those encountered north of Maine, passed over lightly populated areas before they were sampled. None of the biomass particles observed in the plumes had a large $\mathrm{Pb}$ signal. Yet they contained small amounts of $\mathrm{Pb}$ nearly as often as particles from urban plumes.

Figure 11 shows the fraction of biomass-burning particles over eastern Canada that contained $\mathrm{Pb}$ as a function of the amount of sulfate on those particles. For this plume analysis, biomass burning particles were defined by cluster analysis of the mass spectra with the additional constraints of gas phase acetonitrile greater than $250 \mathrm{ppbv}$ and latitude north of $48^{\circ}$. Few particles contained much sulfate, but those that did often contained $\mathrm{Pb}$. In contrast, none of the particles sampled from a fresh biomass burning plume over Utah in 2002 contained measurable $\mathrm{Pb}$ or sulfate (Hudson et al., 2004). The flight with a higher frequency of $\mathrm{Pb}$ (9 July) also encountered more gas phase $\mathrm{SO}_{2}$. The correlation between $\mathrm{Pb}$ and sulfate is a strong indication that the $\mathrm{Pb}$ was added to the particles during transport rather than coming from $\mathrm{Pb}$ in the burning

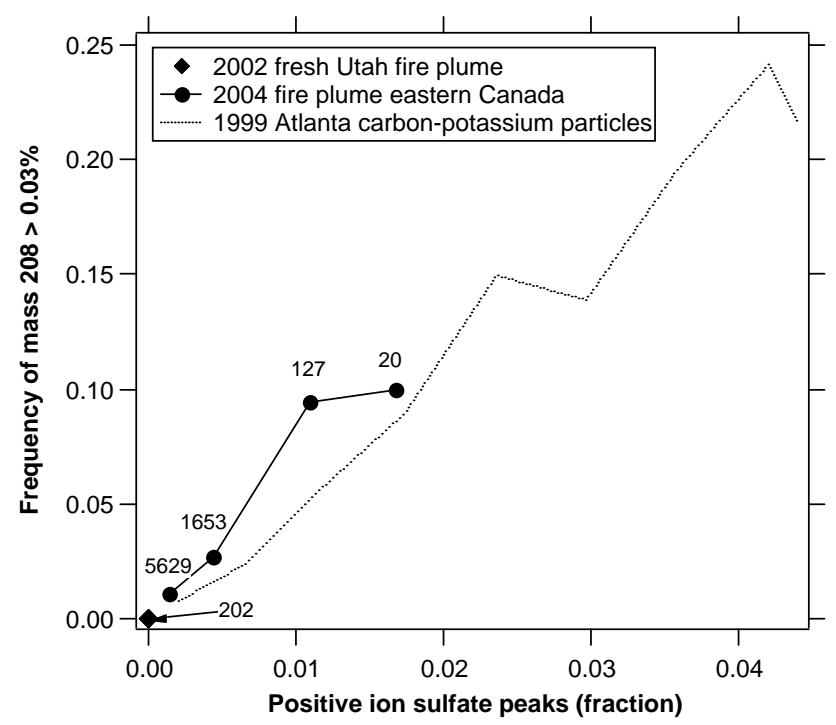

Fig. 11. Frequency of ${ }^{208} \mathrm{~Pb}$ in particles in biomass burning plumes as a function of the sulfate content of those particles. Fire plume points are marked with the number of spectra with sulfate peaks in that range. There were many more particles in the Atlanta dataset.

vegetation or soil. This correlation between sulfate and $\mathrm{Pb}$ in single biomass burning particles was not present for many other types of particles during these flights. The correlation is probably present in these biomass burning plumes because the major airborne $\mathrm{Pb}$ sources between Alaska and eastern Canada are smelters that are also major sources of $\mathrm{SO}_{2}$. In Atlanta, a similar correlation between $\mathrm{Pb}$ and sulfate was also found for carbon-potassium particles but not the entire data set.

\subsection{Asian sources}

Off the coast of California, the high average $\mathrm{Pb}$ signal near $36 \mathrm{~N}$ and $125 \mathrm{~W}$ (Fig. 6) included 59 particles with mass 208 greater than $10 \%$ of the total ion current in a relatively small region. All of these particles were encountered above $2 \mathrm{~km}$, with the majority on a flight leg at $4.9 \mathrm{~km}$. Compared to other $\mathrm{Pb}$-rich particles during the 2002 flights, these had more $\mathrm{K}$ and much less As and Sn. According to a FLEXPART simulation, the time period when they were sampled corresponded with transport from Asia (see http://www.atmos-chem-phys.net/7/3195/ 2007/acp-7-3195-2007-supplement.pdf). Carbon monoxide was moderately elevated to about $120 \mathrm{ppbv}$. This flight period had total aerosol volumes of 1 to $3 \mu \mathrm{m}^{3} \mathrm{~cm}^{-3}$ below $1 \mu \mathrm{m}$ diameter and 1 to $10 \mu \mathrm{m}^{3} \mathrm{~cm}^{-3}$ in the coarse mode. These are unusually large for this altitude and probably mean that there was little scavenging of Asian emissions during this particular transport event.

The IMPROVE data shown in Fig. 3 also suggest transport of $\mathrm{Pb}$ to the western United States in springtime. The 

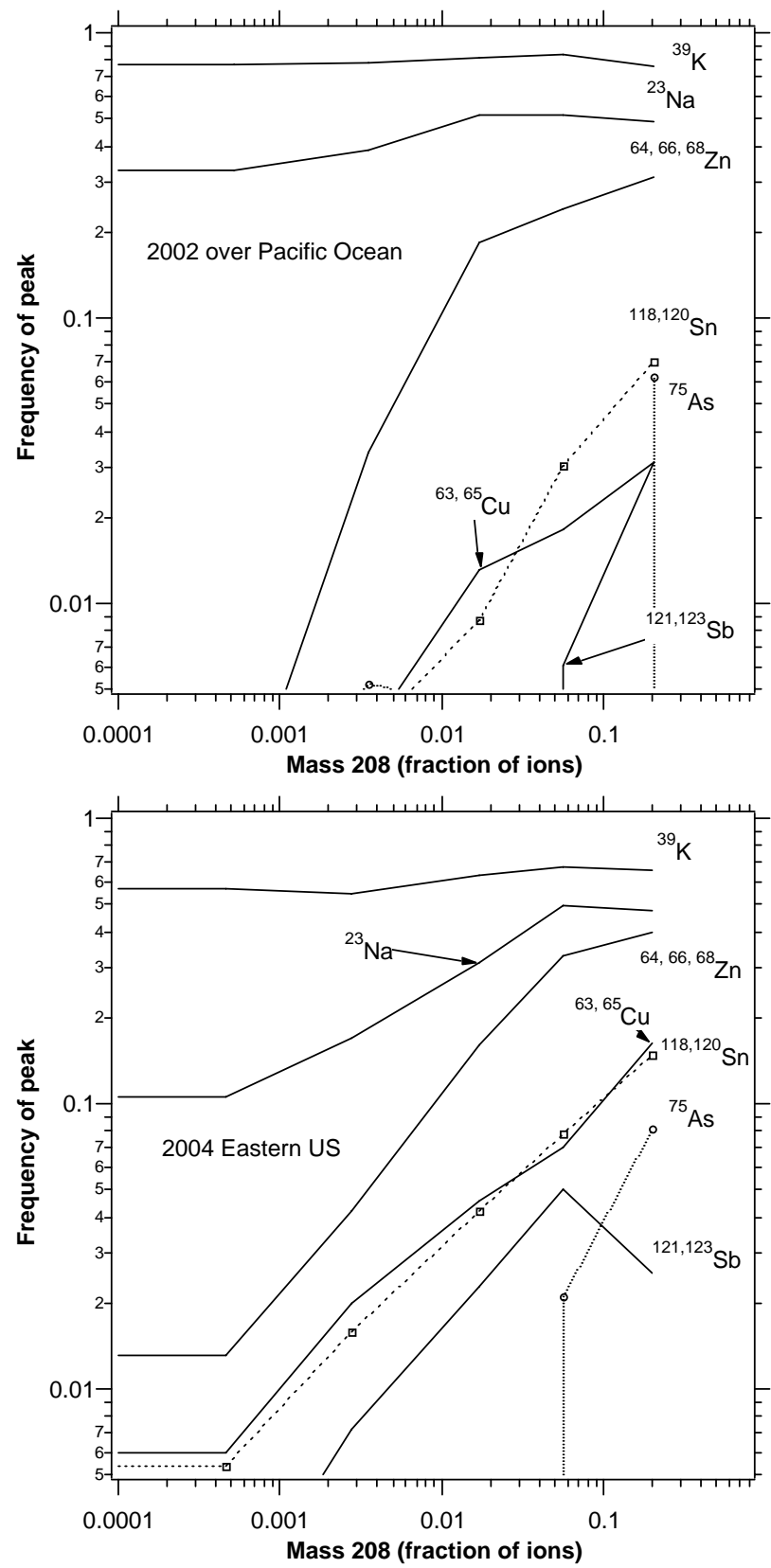

Fig. 12. Frequency of peaks observed by PALMS in particles with various amounts of ${ }^{208} \mathrm{~Pb}$. There may be some small overestimates of other metals due to fragmentation of other species at the same masses. In each case either an isotopic pattern was required, such as the presence of all three $\mathrm{Zn}$ isotopes, or the peak was required to be much larger than neighboring peaks. For arsenic, mass 75 was required to be at least 5 times both 73 and 77 to differentiate As from $\mathrm{CaCl}^{+}$and organic spectra with peaks at every odd mass.

maxima at several western sites in April coincide with the timing of transport from Asia. Particulate matter at three Asian sites and the North Pacific had $\mathrm{Pb} / \mathrm{Zn}$ ratios of 0.6 to 0.8 (Cohen et al., 2004; Narita et al., 1999). Mauna Loa stays near the Asian $\mathrm{Pb} / \mathrm{Zn}$ ratio throughout the year, even when absolute concentrations of both are very low. The Mount Zirkel site at $3243 \mathrm{~m}$ in Colorado is an especially clear example of a site reaching the Asian $\mathrm{Pb} / \mathrm{Zn}$ ratio in the springtime and going to the North American ratio of 0.3 to 0.4 the rest of the year.

Although the signature of transport from Asia is clear, it contributes less than $1 \mathrm{ng} \mathrm{m}^{-3}$ even in springtime in the western United States. Most of the airborne $\mathrm{Pb}$ over the United States cannot be from Asia.

\subsection{Other metals in $\mathrm{Pb}$-rich particles}

The particles that produced large $\mathrm{Pb}$ signals also usually contained other metals. Figure 12 shows the fraction of particles that contained selected other metals as a function of the ion signal from $\mathrm{Pb}$. Particles over the Pacific Ocean west of California and those over the eastern United States had fairly similar frequencies of other metals. The biggest difference is that particles over the ocean were more likely to contain $\mathrm{Na}$. Figure 13 shows the average mass spectra of all particles for which the ${ }^{208} \mathrm{~Pb}$ signal was least $10 \%$ of the total ion signal. In these instruments metals are commonly found as the elemental ion, so there is little information on the chemical form of the metal in the particles. The $\mathrm{PbO}^{+}$ion was occasionally observed.

\subsection{Mechanisms for distributing $\mathrm{Pb}$ among particles}

It seems unlikely that about $10 \%$ of the accumulation mode aerosol particles over the United States originated from sources that emit $\mathrm{Pb}$. The special case of the biomass burning plumes shows that particles can acquire $\mathrm{Pb}$ during atmospheric transport. In addition, particles over a wide range of sizes contained $\mathrm{Pb}$. Two ways that so many particles could contain $\mathrm{Pb}$ are condensation of gas phase $\mathrm{Pb}$ compounds and coagulation with small $\mathrm{Pb}$-rich particles. Of these, it is likely that coagulation is much more important. Gas phase $\mathrm{Pb}$ compounds are present only at very low concentrations (Wang et al., 1997; Shotyk and Le Roux, 2005). Another argument in favor of coagulation is that even in the areas with the most $\mathrm{Pb}$ many mass spectra with excellent signal to noise showed no $\mathrm{Pb}$. This distribution is more easily explained by coagulation than by deposition from the gas phase, which should lead to some $\mathrm{Pb}$ on almost every particle. Finally, $\mathrm{Pb}$-rich particles smaller than $50 \mathrm{~nm}$ aerodynamic diameter were directly observed in urban areas. The coagulation of such particles with larger organic-sulfate particles could explain why some but not all of those particles have $\mathrm{Pb}$. Coagulation of $\mathrm{Pb}$-rich particles onto other particles has been observed with detailed electron microscopy (Utsunomiya et al., 2004; Choël et al., 2006).

Coagulation calculations show that reasonable times are required for 5 or $10 \%$ of accumulation mode particles to acquire $\mathrm{Pb}$ by coagulation with smaller, $\mathrm{Pb}$-rich particles. 

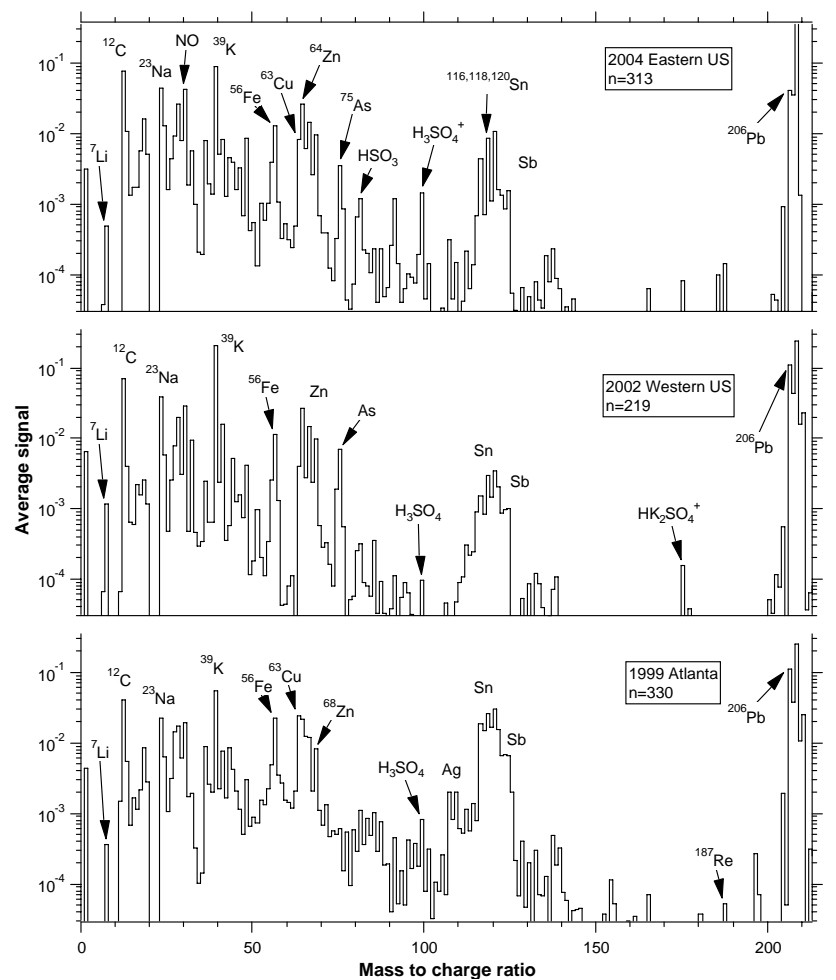

Fig. 13. Averages of PALMS mass spectra with mass 208 greater than $10 \%$ of the ion current. The $\mathrm{Pb}$ isotope pattern is not accurate since it is dominated by whether or not the peak-finding routines found 206 and 207.

Figure 14 shows the time required for accumulation mode particles to acquire $\mathrm{Pb}$ by coagulation with a constant $100 \mathrm{~cm}^{-3}$ concentration of smaller, $\mathrm{Pb}$-rich particles. When expressed as a fraction of particles, this time constant is independent of the concentration of accumulation mode particles. The times will be shorter or longer depending on the concentration of small particles. These calculations are from expressions in Table 10.1 of Seinfeld (1986) for $2 \mathrm{~km}$ altitude and small and larger particle densities of 2.5 and $1.5 \mathrm{~g} \mathrm{~cm}^{-3}$, respectively, although the calculation is not very sensitive to these parameters. A factor of 1.25 was used as an estimate for the effect of van der Waals forces.

Figure 14 also indicates that coagulation with the assumed ultrafine particles is faster for larger particles. For the case discussed earlier of the biomass burning plume of Canada, particles with vacuum aerodynamic diameters larger than $700 \mathrm{~nm}$ were about twice as likely to contain $\mathrm{Pb}$ than particles smaller than $400 \mathrm{~nm}$. This is consistent with the coagulation calculation, although it is difficult to compare in detail because the size of the original $\mathrm{Pb}$-containing particles is not known and the accumulation mode particles change size during transport due to condensation of sulfates and other species.

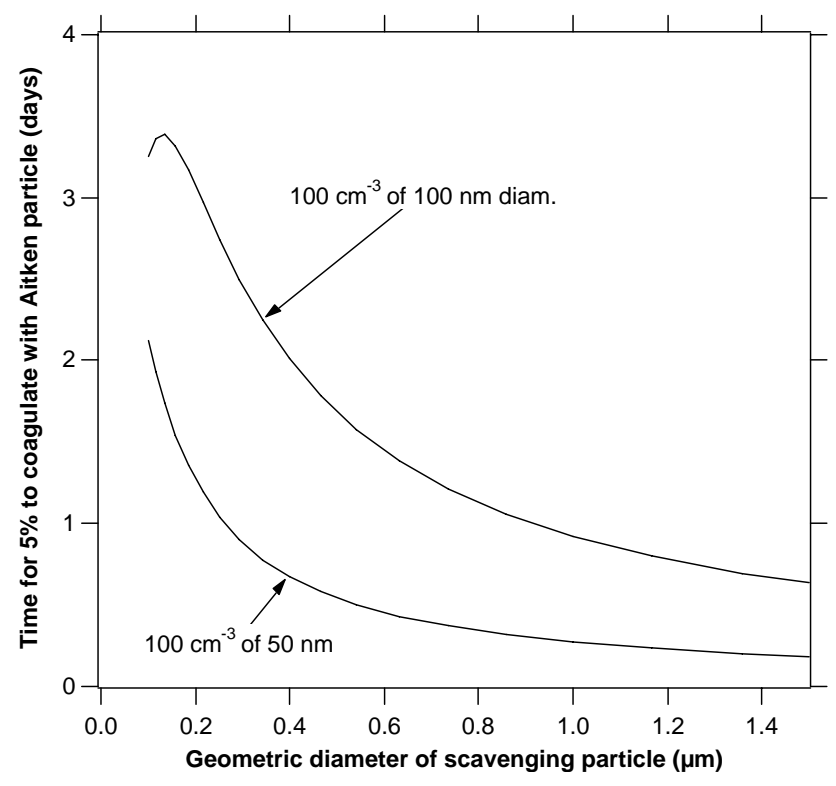

Fig. 14. The time required for $5 \%$ of accumulation mode particles of a given diameter to coagulate with a constant background of smaller particles.

\section{Conclusions}

Lead has been observed in particles over a wide size range from less than $50 \mathrm{~nm}$ to more than $2 \mu \mathrm{m}$. Expressed as a fraction of the total aerosol, there was little gradient in $\mathrm{Pb}$ with altitude from the top of the boundary layer to the tropopause. Across a wide range of locations, altitudes, and particle chemistry, more than $5 \%$ of particles contain small amounts of $\mathrm{Pb}$. There was a wide range of the amount of $\mathrm{Pb}$ in individual particles. A significant fraction of the total $\mathrm{Pb}$ signal comes from a few particles that contain large amounts of $\mathrm{Pb}$. These particles often contain other metals, especially $\mathrm{Zn}$. Many of the $\mathrm{Pb}$-containing particles by number have very small $\mathrm{Pb}$ signals and are otherwise similar to particles without $\mathrm{Pb}$. In Atlanta, Wilmington, and other urban areas the $\mathrm{Pb}$-rich particles had a strong dependence on wind direction but the particles with small $\mathrm{Pb}$ signals were almost independent of wind direction.

These particles with small amounts of $\mathrm{Pb}$ may be the result of coagulation of smaller particles with accumulation mode aerosol. For the United States, the largest sources of airborne $\mathrm{Pb}$ are aviation gasoline, coal combustion, and smelters. All of these are combustion sources that can produce very small particle. The fraction of $\mathrm{Pb}$ in coal that becomes airborne and the $\mathrm{Pb}$ content of residual fuel oil are two parameters that could significantly affect the budget of airborne $\mathrm{Pb}$. One special example of $\mathrm{Pb}$ interacting with aerosols was that some particles in a biomass burning plume acquired both $\mathrm{Pb}$ and sulfate as the plume traversed Canada, probably from smelters along the way. 
The percentage of particles containing $\mathrm{Pb}$ was as high or higher over the Pacific Ocean west of California than it was over the continental United States. Some of this $\mathrm{Pb}$ is clearly due to long-range transport from Asia. On an absolute basis, however, North American sources were more important to $\mathrm{Pb}$ in the eastern United States. The overall fraction of particles with detectable $\mathrm{Pb}$ was also similar at a high altitude site in Switzerland to measurements in the United States. In both continents there was little size dependence and there was a wide range of $\mathrm{Pb}$ contents in individual particles. In both continents most of the particles with the highest $\mathrm{Pb}$ contents contained other metals whereas particles with very small $\mathrm{Pb}$ contents were similar to those without any $\mathrm{Pb}$.

The special capabilities of single particle mass spectrometry were essential to obtaining these results. Only the measurement of large numbers of particles could obtain statistically significant samples of $\mathrm{Pb}$-rich particles. High sensitivity was required to measure the small amounts of $\mathrm{Pb}$ in many other particles. The results show a very geographically broad distribution of $\mathrm{Pb}$ in particles, consistent with multiple sources. These are some of the first data showing that $\mathrm{Pb}$ is present in particles in the free troposphere. The way $\mathrm{Pb}$ is distributed among different types of particles will affect how airborne $\mathrm{Pb}$ enters both the human lung and ecosystems.

Acknowledgements. Funding by the Collaborative Research Center 641 "The Tropospheric Ice Phase" of the German Research Foundation is gratefully acknowledged for the Jungfraujoch measurements. Funding by the United States Environmental Protection Agency under grant number XA-97309801 is gratefully acknowledged for the Wilmington RSMS measurements. We thank $\mathrm{B}$. Linak and M. Murphy for pointing out some references on $\mathrm{Pb}$ in fuels.

Edited by: M. Ammann

\section{References}

Ali, M. F., Cukhari, A., and Saleem, M.: Trace metals in crude oils from Saudi Arabia, Ind. Eng. Chem. Prod. Res. Dev., 22, 691694, 1983.

Alvarez, F. F., Rodríguez, M. T., Espinosa, A. J. F., and Dabán, A. G.: Physical speciation of arsenic, mercury, lead, cadmium and nickel in inhalable atmospheric particles, Anal. Chimica Acta, 524, 33-40, 2004.

Baltensperger, U., Gaggeler, H. W., Jost, D.T., Lugauer, M., Schwikowski, M., Weingartner, E., and Seibert, P.: Aerosol climatology at the high-alpine site Jungfraujoch, Switzerland, J. Geophys. Res., 102(D16), 19707-19715, 1997.

Bein, K. J., Zhao, Y., Wexler, A. S., and Johnston, M. V.: Speciation of size-resolved individual ultrafine particles in Pittsburgh, Pennsylvania, J. Geophys. Res., 110, D07S05, doi:10.1029/2004JD004708, 2005.

Bein, K. J., Zhao, Y., Pekney, N. J., Davidson, C. I., Johnston, M. V., and Wexler, A. S.: Identification of sources of atmospheric PM at the Pittsburgh Supersite. Part II: Quantitative comparisons of single particle, particle number, and particle mass measurements", Atmos. Environ., 40, S424-S444, 2006.

Boughton, B. and Horvath, A.: Environmental assessment of used oil management methods, Environ. Sci. Technol., 38, 353-358, 2004.

Bratzel Jr., M. P. and Chakrabarti, C. L.: Determination of lead in petroleum and petroleum products by atomic absorption spectrometry using a carbon rod analyzer, Anal. Chim. Acta, 61, 2532, 1972.

Bukowiecki, N., Hill, M., Gehrig, R., Zwicky, C. N., Lienemann, P., Hegedüs, F., Falkenberg, G., Wingartner, E., and Baltensperger, U.: Trace metals in ambient air: Hourly size-segregated mass concentrations determined by synchrotron-XRF, Environ. Sci. Technol., 39, 5754-5762, 2005.

Choël, M., Deboudt, K., Flament, P., Lecornet, G., Perdrix, E., and Sobanska, S.: Fast evolution of tropospheric $\mathrm{Pb}$ - and $\mathrm{Zn}$-rich particles in the vicinity of a lead smelter, Atmos. Environ., 40, 4439-4449, 2006.

Cohen, D. D., Garton, D., Stelcer, E., Hawa, O., Wang, T., Poon, S., Kim, J., Choi, B. C., Oh, S. N., Shin, H.-J., Ko, M. Y., and Uematsu, M.: Multielemental analysis and characterization of fine aerosols at several key ACE-Asia sites, J. Geophys. Res., 109, D19S12, doi:10.1029/2003JD003569, 2004.

Cziczo, D. J., Thomson, D. S., and Murphy, D. M.: Ablation, flux, and atmospheric implications of meteors inferred from stratospheric aerosol, Science, 291, 1772-1775, 2001.

Davison, R. L., Natusch, D. F. S., Wallace, J. R., and Evans Jr., C. A.: Trace elements in fly ash: Dependence of concentration on particle size, Environ. Sci. Technol., 8, 1107-1113, 1974.

De Gouw, J. A., Warneke, C., Stohl, A., Wollny, A. G., Brock, C. A., Cooper, O. R., Holloway, J. S., Trainer, M., Fehsenfeld, F. C., Atlas, E. L., Donnelly, S. G., Stroud, V., and Lueb, A.: Volatile organic compounds composition of merged and aged forest fire plumes from Alaska and western Canada, J. Geophys. Res., 111, D10303, doi:10.1029/2005JD0006175, 2006.

Dreyfus, S., Pécheyran, C., Magnier, C., Prinzhofer, A., Lienemann, C. P., and Donard, O. F. X.: Direct trace and ultra-trace metals determination in crude oil and fractions by inductively coupled mass spectrometry, J. ASTM International, 2, 1-8, 2005.

Environmental Protection Agency: Latest findings on National Air Quality, 2002 Status and Trends, U.S. Environmental Protection Agency, http://www.epa.gov/air/airtrends/aqtrnd02/ 2002_airtrends_final.pdf, 2003.

Flagan, R. C. and Taylor, D. D.: Laboratory studies of submicron particles from coal combustion, Eighteenth Symposium on Combustion, 1227-1237, The Combustion Institute, 1981.

Gard, E., Mayer, J. E., Morrical, B. D., Dienes, T., Fergenson, D. P., and Prather, K. A.: Real-time analysis of individual atmospheric aerosol particles: Design and performance of a portable ATOFMS, Anal. Chem. 69, 4083-4091, 1997.

Gokhale, S. B. and Patil, R. S.: Size distribution of aerosols (PM10) and lead $(\mathrm{Pb})$ near traffic intersections in Mumbai (India), Environ. Mon. Assessment, 95, 311-324, 2004.

Han, J. S., Moon, K. J., Ryu, S. Y., Kim, Y. J., and Perry, K. D.: Source estimation of anthropogenic aerosols collected by a DRUM sampler during spring of 2002 at Gosan, Korea, Atmos. Environ., 39, 3113-3125, 2005.

Heathcote, R., Simmons, D., and Bernholtz, S.: Analysis of motorvehicle fuels for metals by inductively coupled plasma-mass 
spectrometry, Iowa Ground Water Quarterly, 39, 1-4, 2000.

Hudson, P. K., Murphy, D. M., Cziczo, D. J., Thomson, D. S., de Gouw, J. A., Warneke, C., Holloway, J., Jost, H.-J., and Hübler, G.: Biomass burning particle measurements: Characteristic composition and chemical processing, J. Geophys. Res., 109, D23S27, doi:10.1029/2003JD004398, 2004.

Kaufmann, R. L.: Laser-microprobe mass spectroscopy (LAMMA) of particulate matter, Physical and Chemical Characterization of Individual Airborne Particles, edited by: Spurny, K. R., Ellis \& Horwood Ltd., Chichester, 1986.

Lake, D. A., Tolocka, M. P., Johnston, M. V., and Wexler, A. S.: Mass spectrometry of individual particles between 50 and $750 \mathrm{~nm}$ in diameter at the Baltimore Supersite, Environ. Sci. Technol., 37, 3268-3274, 2003.

Lee, S.-H., Murphy, D. M., Thomson, D. S., and Middlebrook, A. M.: Chemical components of single particles measured with Particle Analysis by laser Mass Spectrometry (PALMS) during the Atlanta SuperSite Project: Focus on organic/sulfate, lead, soot, and mineral particles, J. Geophys. Res., 107, AAC 1, doi:10.1029/2000JD000011, 2002.

Linak, W. P. and Wendt, J. O. L.: Toxic metal emissions from incineration: Mechanisms and control, Prog. Energy Comb. Sci., 19, 145-185, 1993.

Magaw, R. I., McMillen, S. J., Gala, W. R., Trefry, J. H., and Trocine, R. P.: Risk evaluation of metals in crude oils, Proc. 6th Int. Petrol. Environ. Conf., 16-18 November, Houston, TX, 460473, 1999.

Malm, W. C., Sisler, J. F., Huffman, D., Eldred, R. A., and Cahill, T. A.: Spatial and Seasonal Trends in Particle Concentration and Optical Extinction in the United-States, J. Geophys. Res., 99, 1347-1370, 1994.

Maenhaut, W., Cafmeyer, J., Dubtsov, S., and Chi, X.: Detailed mass size distributions of elements and species, and aerosol chemical mass closure during fall 1999 at Gent, Belgium, Nucl. Instrum. Methods Phys. Res. B., 189, 238-242, 2002.

Mallina, R. V., Wexler, A. S., Rhoads, K. P., and Johnston, M. V.: High speed particle beam generation: A dynamic focusing mechanism for selecting ultrafine particles, Aerosol Sci. Technol., 33, 87-104, 2000.

Miller, C. A., Ryan, J. V., and Lombardo, T.: Characterization of air toxics from an oil-fired firetube boiler, J. Air Waste Manage. Assoc., 46, 742-748, 1996.

Murphy, D. M., Cziczo, D. J., Froyd, K. D., Hudson, P. K., Matthew, B. M., Middlebrook, A. M., Peltier, R. E., Sullivan, A., Thomson, D. S., and Weber, R. L.: Single-particle mass spectrometry of tropospheric aerosol particles, J. Geophys. Res., 111, D23S32, doi:10.1029/2006JD007340, 2006.

Narita, U., Tanaka, S., and Santosa, S. J.: A study on the concentration, distribution, and behavior of metals in atmospheric particulate matter over the North Pacific Ocean by using inductively coupled plasma mass spectrometry equipped with laser ablation, J. Geophys. Res., 104, 26 859-26 866, 1999.

Nriagu, J. O., Lawson, G., Wong, H. K., and Azcue, J. M.: A protocol for minimizing contamination in the analysis of trace metals in Great Lakes waters, J. Great Lakes Res., 19, 175-182, 1993.

Phares, D. J., Rhoads, K. P., Johnston, M. V., and Wexler, A. S.: Size-resolved ultrafine particle composition analysis, Part 2: Houston, J. Geophys. Res., 108(D7) 8420, doi:10.1029/2001JD001212, 2003.
Raask, E.: The mode of occurrence and concentration of trace elements in coal, Prog. Energy. Combust. Sci., 11, 97-118, 1985.

Rhoads, K. P., Phares, D. J., Wexler, A. S., and Johnston, M. V.: Size-resolved ultrafine particle composition analysis, Part 1: Atlanta, J. Geophys. Res., 108(D7) 8418, doi:10.1029/2001JD001211, 2003.

Rising, B., Wu, J., and Sorurbakhsh, P.: Survey of ultra-trace metals in gas turbine fuels, 11th Annual International Petroleum Environmental Conference, 12-15 October 2004.

Salma, I., Maenhaut, W., and Záray, G.: Comparative study of elemental mass size distributions in urban atmospheric aerosol, J. Aerosol Sci., 22, 339-356, 2002.

Seinfeld, J. H.: Air Pollution, Wiley and Sons, New York, 738 pp., 1986.

Shotyk, W. and Le Roux, G.: Biogeochemistry and Cycling of Lead, in: Biogeochemical Cycles of the Elements, vol. 43 of Metal Ions in Biological Systems, edited by: Sigel, A., Sigel, H., and Sigel, R. K. O., M. Dekker, New York, pp. 240-275, 2005.

Shotyk, W., Zheng, J., Krachler, M., Zdanowicz, C., Koemer, R., and Fisher, D.: Predominance of industrial $\mathrm{Pb}$ in recent snow (1994-2004) and ice (1842-1996) from Devon Island, Arctic Canada, Geophys. Res. Lett., 32, L21814, doi:10.1029/2005GL023860, 2005.

Shumway, L. A.: Trace element and polycyclic aromatic hydrocarbon analyses of jet engine fuels: Jet A, JP5, and JP8, Technical Report 1845, SPAWAR Systems Center, San Diego, 2000.

Singh, M., Jaques, P. A., and Sioutas, C.: Size distribution and diurnal characteristics of particle-bound metals in source and receptor sites of the Los Angeles Basin, Atmos. Environ., 36, 16751689, 2002.

Solomon, P. A., Chameides, W., Weber, R., Middlebrook, A., Kiang, C. S., Russell, A. G., Butler, A., Turpin, B., Mikel, D., Scheffe, R., Cowling, E., Edgerton, E., St. John, J., Jansen, J., McMurry, P., Hering, S., and Bahadori, T.: Overview of the 1999 Atlanta Supersite Project, J. Geophys. Res., 108(7), 8413, doi:10.1029/1002JD001458, 2003.

Stohl, A., Forster, C., Frank, A., Seibert, P., and Wotawa, G.: Technical note: The Lagrangian particle dispersion model FLEXPART version 6.2, Atmos. Chem. Phys., 5, 2461-2474, 2005, http://www.atmos-chem-phys.net/5/2461/2005/.

Tan, M. G., Zhang, G. L., Li, X. L., Zhang, Y. X., Yue, W. S., Chen, J. M., Wang, Y. S., Li, A. G., Li Y., Zhang, Y. M., and Shan, Z. C.: Comprehensive study of lead pollution in Shanghai by multiple techniques, Anal. Chem., 78, 8044-8050, 2006.

Thomson, D. S., Schein, M. E., and Murphy D. M.: Particle analysis by laser mass spectrometry WB-57F instrument overview, Aerosol Sci. Technol., 33, 153-169, 2000.

Tolocka, M. P., Lake, D. A., Johnston, M. V., and Wexler, A. S.: Number concentrations of fine and ultrafine particles containing metals, Atmos. Environ., 38, 3263-3273, 2004.

Tolocka, M. P., Lake, D. A., Johnston, M. V., and Wexler, A. S.: Size-resolved fine and ultrafine particle composition in Baltimore, Maryland, J. Geophys. Res., 110, D07S04, doi:10.1029/2004JD004573, 2005.

Utsunomiya, S., Jensen, K. A., Keeler, G. J., and Ewing, R. C.: Direct identification of trace metals in fine and ultrafine particles in the Detroit urban atmosphere, Environ. Sci. Technol., 38, 22892297, 2004.

Vermont Department of Environmental Conservation: Vermont 
used oil analysis and waste oil furnace emissions study, Waterbury, Vermont, 1994.

Wang, Y., Turnbull, A. B., and Harrison, R. M.: Concentrations, phase partitioning, and deposition of specific alkyl-lead compounds in the atmosphere, Appl. Organometallic Chem., 11, 899-901, 1997.
Widory, D., Roy, S., Le Moullec, Y., Goupil, G., Cocherie, A., and Guerrot, C.: The origin of atmospheric particles in Paris: a view through carbon and lead isotopes, Atmos. Environ., 38, 953-961, 2004. 